\title{
The anti-caspase inhibitor Q-VD-OPH prevents AIDS disease progression in SIV-infected rhesus macaques
}

\author{
Mireille Laforge, ${ }^{1}$ Ricardo Silvestre, ,2,3 Vasco Rodrigues, ${ }^{1,4,5}$ Julie Garibal,, ${ }^{1}$ Laure Campillo-Gimenez, ${ }^{1}$ Shahul Mouhamad, ${ }^{1}$ \\ Valérie Monceaux, ${ }^{6}$ Marie-Christine Cumont, ${ }^{6}$ Henintsoa Rabezanahary, ${ }^{7}$ Alain Pruvost, ${ }^{8}$ Anabela Cordeiro-da-Silva, ${ }^{4,5}$ \\ Bruno Hurtrel, ${ }^{6}$ Guido Silvestri, ${ }^{9}$ Anna Senik, ${ }^{1}$ and Jérôme Estaquier ${ }^{1,7}$
}

'CNRS FR 3636, Université Paris Descartes, Paris, France. ${ }^{2}$ Microbiology and Infection Research Domain, Life and Health Sciences Research Institute (ICVS), School of Medicine, University of Minho, Braga, Portugal. IICVS/3B's - PT Government Associate Laboratory, Braga/Guimarães, Portugal. 4i3S - Instituto de Investigação e Inovação em Saúde and Instituto de Biologia Molecular e Celular, Universidade do Porto, Porto, Portugal. ' Enité de Physiopathologie des Infections Lentivirales, Institut Pasteur, Paris, France. 'Université Laval, Centre de Recherche du CHU de Québec, Quebec City, Quebec, Canada. ${ }^{8}$ CEA,

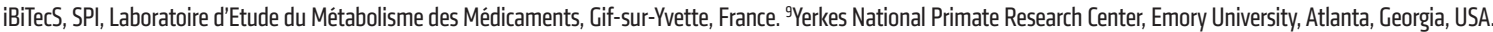

\begin{abstract}
Apoptosis has been proposed as a key mechanism responsible for $\mathrm{CD4}^{+} \mathrm{T}$ cell depletion and immune dysfunction during HIV infection. We demonstrated that Q-VD-OPH, a caspase inhibitor, inhibits spontaneous and activation-induced death of T cells from SIV-infected rhesus macaques (RMs). When administered during the acute phase of infection, Q-VD-OPH was associated with (a) reduced levels of $\mathrm{T}$ cell death, (b) preservation of $\mathrm{CD} 4^{+} / \mathrm{CD} 8^{+} \mathrm{T}$ cell ratio in lymphoid organs and in the gut, (c) maintenance of memory CD4+ $\mathrm{T}$ cells, and (d) increased specific CD4+ $\mathrm{T}$ cell response associated with the expression of cytotoxic molecules. Although therapy was limited to the acute phase of infection, Q-VD-OPH-treated RMs showed lower levels of both viral load and cell-associated SIV DNA as compared with control SIV-infected RMs throughout the chronic phase of infection, and prevented the development of AIDS. Overall, our data demonstrate that Q-VD-OPH injection in SIV-infected RMs may represent an adjunctive therapeutic agent to control HIV infection and delaying disease progression to AIDS.
\end{abstract}

\section{Introduction}

Pathogenic HIV and SIV infections of humans and rhesus macaques (RMs), respectively, are associated with progressive $\mathrm{CD}^{+} \mathrm{T}$ cell depletion and having a short half-life $(1,2)$. The regulation of $\mathrm{T}$ lymphocyte numbers that occurs physiologically during any normal immune response (i.e., the contraction phase) is accomplished by the concerted action of two fundamental biological mechanisms, known as activation-induced cell death (AICD) and death by neglect or cytokine deprivation. AICD, which acts to limit the accumulation of $\mathrm{T}$ cells that have responded to a certain antigen, is dependent on the death receptor CD95/Fas and associated with the activation of cysteine proteases (caspases) leading to apoptosis. As antigen levels decrease, growth factors and cytokines also become scarce, activating the proapoptotic Bcl-2 family member Bim, which engages the mitochondrial pathway of apoptosis (3-5). The cooperative interplay between these two mechanisms of cell death ensures the elimination of most effector T cells as the system returns to the steady state, while allowing the survival of a small pool of long-living, self-sustaining memory T cells.

Studies conducted in both pathogenic and nonpathogenic models of SIV infection have demonstrated a direct correlation between progression to AIDS and the levels of CD4 ${ }^{+} \mathrm{T}$ cell apoptosis early after infection (6-17). In the context of HIV/SIV infections, the increased level of apoptosis can be related to the pres-

Conflict of interest: The authors have declared that no conflict of interest exists Submitted: June 16, 2017; Accepted: February 7, 2018.

Reference information: / Clin Invest. 2018;128(4):1627-1640.

https://doi.org/10.1172/JCI95127. ence of heightened levels of immune activation (18-20). CD4 ${ }^{+}$ T cells from HIV-infected individuals and SIV-infected RMs are highly sensitive to Fas-mediated apoptosis (9, 14, 21-24), which is prevented by caspase inhibitors such as Z-VAD-FMK $(10,14,21$, 25-27). However, Z-VAD-FMK interferes with cell proliferation $(28,29)$, thus limiting its potential for clinical use. Furthermore, we and others have also shown that the proapoptotic proteins Bim and Bak are upregulated in $\mathrm{CD} 4^{+} \mathrm{T}$ cells from chronically HIV-infected individuals and in SIV-infected RMs compared with healthy donors $(14,30)$. However, spontaneous $\mathrm{T}$ cell death was prevented only to a limited extent by Z-VAD-FMK but prevented by cytokines $(9,14,21,31,32)$.

In addition to viral replication (33-39), in which lysosome destabilization is of crucial importance (40), cell death of CD4 ${ }^{+}$ $T$ cells can be mediated by viral particles, often defective, that can still bind to - and enter into - $\mathrm{CD} 4^{+} \mathrm{T}$ cells; viral particles thus represent potential candidates for the killing of $\mathrm{CD} 4^{+} \mathrm{T}$ cells in the absence of productive infection (11, 23, 24, 41-50). Therefore, the HIV-1 envelope protein induces the activation of caspase- 3 and caspase-8 $(47,51)$. Whereas Z-VAD-FMK poorly inhibits spontaneous cell death (14), other groups have proposed that quiescent $\mathrm{CD}^{+} \mathrm{T}$ cells die by caspase-1-mediated cell death triggered by abortive viral infections, which initiate inflammatory reactions (52), or even by autophagy (53). Thus, several proteases have been proposed to regulate the death of primary $\mathrm{CD}^{+}{ }^{+} \mathrm{T}$ cells in the context of HIV/SIV infections, and these could serve as therapeutic targets. Until now, very few interventions have been tested in vivo to prevent $\mathrm{CD}^{+}{ }^{+} \mathrm{T}$ cells death in the context of HIV/SIV infections.

In this study, we found that Q-VD-OPH, a broad caspase inhibitor, reduces spontaneous and Fas-mediated apoptosis in 
A

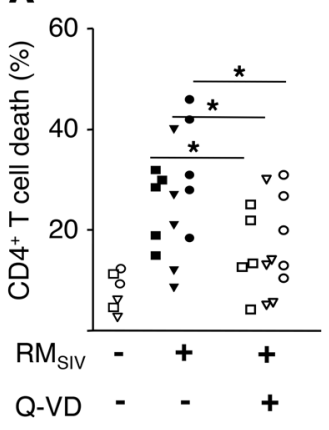

D
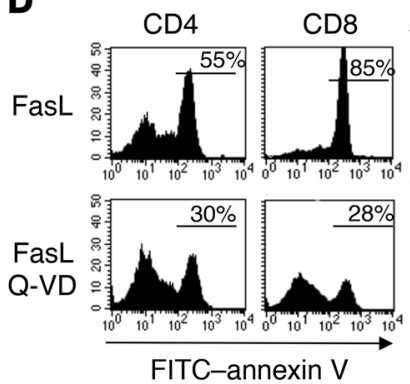

B

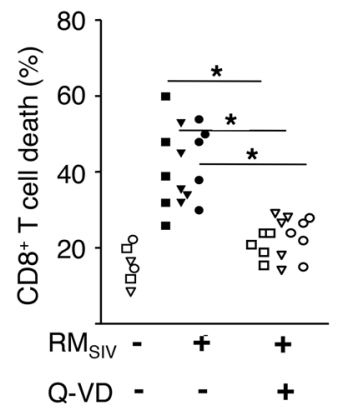

E
C

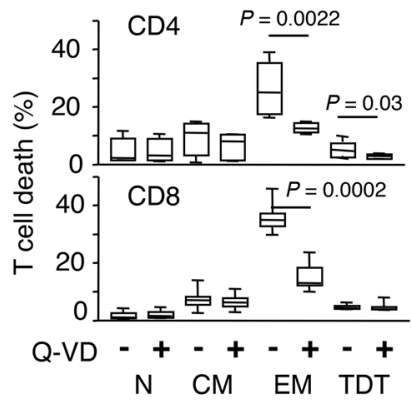

Figure 1. Q-VD-OPH prevents ex vivo cell death and enhances proliferation of T cells from SIV-infected RMs. Percentage of dying (A) CD $3^{+} C D 4^{+}$and (B) $\mathrm{CD}^{+} \mathrm{CD}^{+} \mathrm{T}$ cells from axillary (squares) and inguinal (triangles) LNs and from the spleen (circles) of either healthy RMs (RM ${ }_{\text {SIV }}-; ; n=2$ ) or chronically SIV-infected RMs (RM $\mathrm{SIV},+; n=5$ ) in the absence (-, filled symbols) or presence of Q-VD-OPH (Q-VD) (+, open symbols). Animals were sacrificed 6 months after infection. Statistical significance was assessed using Wilcoxon's matched-pairs signed rank test (1-tailed $P<0.05)$. (C) Percentage of dying CD3+CD4+ and $\mathrm{CD}^{+} \mathrm{CD8}^{+} \mathrm{T}$ subsets (naive [N], CD45RA+CD62L+; Tcm [CM], CD45RA-CD62L+; Tem [EM], CD45RA-CD62L-; terminally differentiated T [TDT] cells, $\left.\mathrm{CD}_{5} \mathrm{RA} \mathrm{C}^{+} \mathrm{CD}_{2} \mathrm{~L}^{-}\right)$from peripheral blood of SIV-infected RMs $(n=6)$ in the absence (-) or presence (+) of Q-VD-OPH. (D) Representative flow cytometric analysis of phosphatidylserine residue exposure (annexin $\mathrm{V}$ staining) on $\mathrm{CD} 3^{+} \mathrm{CD} 4^{+}$and $\mathrm{CD} 3^{+} \mathrm{CD} 8^{+} \mathrm{T}$ cells from peripheral blood of a chronically SIV-infected RM incubated overnight in the presence of FasL. (E) Histogram of CD3+CD4+0 and CD3+CD8 ${ }^{+}$T cells from either healthy (gray boxes, $n=6$ ) or SIV-infected RMs (white boxes, $n=8$ ) incubated with FasL in the absence (-) or presence (+) of Q-VD-OPH. (F) PBMCs from SIV-infected RMs ( $n=6)$ were stimulated with ConA in the absence or presence of Q-VD-OPH. AICD was assessed after overnight culture by flow cytometry using annexin V. Histogram represents the preventive effect calculated as 100 x ((cells untreated - cells+Q-VD)/cells untreated). Statistical significance was assessed using paired Student's $t$ test. Prism was used to present the results in box-and-whisker plots showing the minimum and maximum of all the data. $P<0.05$.

cells recovered from the lymphoid organs of SIVmac251-infected RMs. Furthermore, we demonstrated that in vivo administration of Q-VD-OPH during the acute phase of SIV infection reduced the levels of memory $\mathrm{CD} 4^{+} \mathrm{T}$ cell apoptosis, while maintaining the $\mathrm{CD} 4^{+} /$ $\mathrm{CD}^{+} \mathrm{T}$ cell ratio and preserving the pool of memory $\mathrm{CD} 4^{+} \mathrm{T}$ cells, leading to activation of specific effector $\mathrm{CD} 4^{+} \mathrm{T}$ cells and expression of cytotoxic molecules. Most importantly, Q-VD-OPH-treated RMs exhibited reduced viral load and delayed progression to AIDS.

\section{Results}

$Q-V D-O P H$ inhibits in vitro spontaneous and activation-mediated $T$ cell death. Several proteases (including cysteines, serine, and calpain proteases) have been proposed as regulating the death of primary $\mathrm{CD}^{+} \mathrm{T}$ cells in the context of HIV/SIV infections. Given the lower impact of Z-VAD-FMK on spontaneous cell death, we assessed the effectiveness of different compounds in preventing cell death either spontaneously or after incubation with Fas ligand (FasL). Several synthetic protease inhibitors, including an inhibitor of autophagy (3-MA), cathepsin inhibitors (Z-FG-NHOBzME), calpain inhibitors (ALLN, Z-FA-CHO, calpeptin, and calpastatin), serine protease inhibitors (AEBSF, aprotinin, Elastinal, and TLCK), cysteine protease inhibitors (E-64 and leupeptin), aspartic protease inhibitor (pepstatin A), metalloprotease inhibi- tors (1, 10-phenanthroline), and a broad caspase inhibitor (Q-VD$\mathrm{OPH}$ ) were tested ex vivo using $\mathrm{T}$ cells isolated from chronically SIV-infected RMs. Our results showed that Q-VD-OPH inhibits spontaneous cell death of $\mathrm{CD}^{+}{ }^{+} \mathrm{T}$ cells isolated from peripheral lymph nodes (LNs) (axillary and inguinal) and spleen of SIVinfected RMs (axillary, 24.9\% $\pm 3.33 \%$ versus $15.4 \% \pm 4.59 \%, P=$ 0.019; inguinal, $21.7 \% \pm 5.6 \%$ versus $13.5 \% \pm 4.52 \%, P=0.006$; spleen, $33.1 \% \pm 4.9 \%$ versus $20.2 \% \pm 3.92 \%, P=0.012$, for control and Q-VD-OPH-treated cells, respectively) (Figure 1A). The effect was not restricted to $\mathrm{CD}^{+} \mathrm{T}$ cells, since death of $\mathrm{CD} 8^{+} \mathrm{T}$ cells of SIV-infected RMs was similarly inhibited (axillary, $41 \% \pm 6 \%$ versus $20.7 \% \pm 1.6 \%, P=0.017$; inguinal, $39.9 \% \pm 3.9 \%$ versus $23.1 \%$ $\pm 2.9 \%, P=0.007$; spleen, $44 \% \pm 4.4 \%$ versus $23.1 \% \pm 2.27 \%, P$ $=0.0009$, for control and Q-VD-OPH-treated cells, respectively), and reached the levels observed for $\mathrm{CD}^{+} \mathrm{T}$ cells isolated from healthy RMs (Figure 1B). The other compounds tested had no preventive effect (data not shown).

Because we have previously observed that Z-VAD-FMK was only partly effective in blocking spontaneous T cell death (14), in a cell-free system, using recombinant effector caspases as targets, we compared the two inhibitors. We demonstrated that Q-VDOPH was more effective than Z-VAD-FMK in blocking caspase-3and caspase-7-mediated poly(ADP-ribose) polymerase (PARP) 

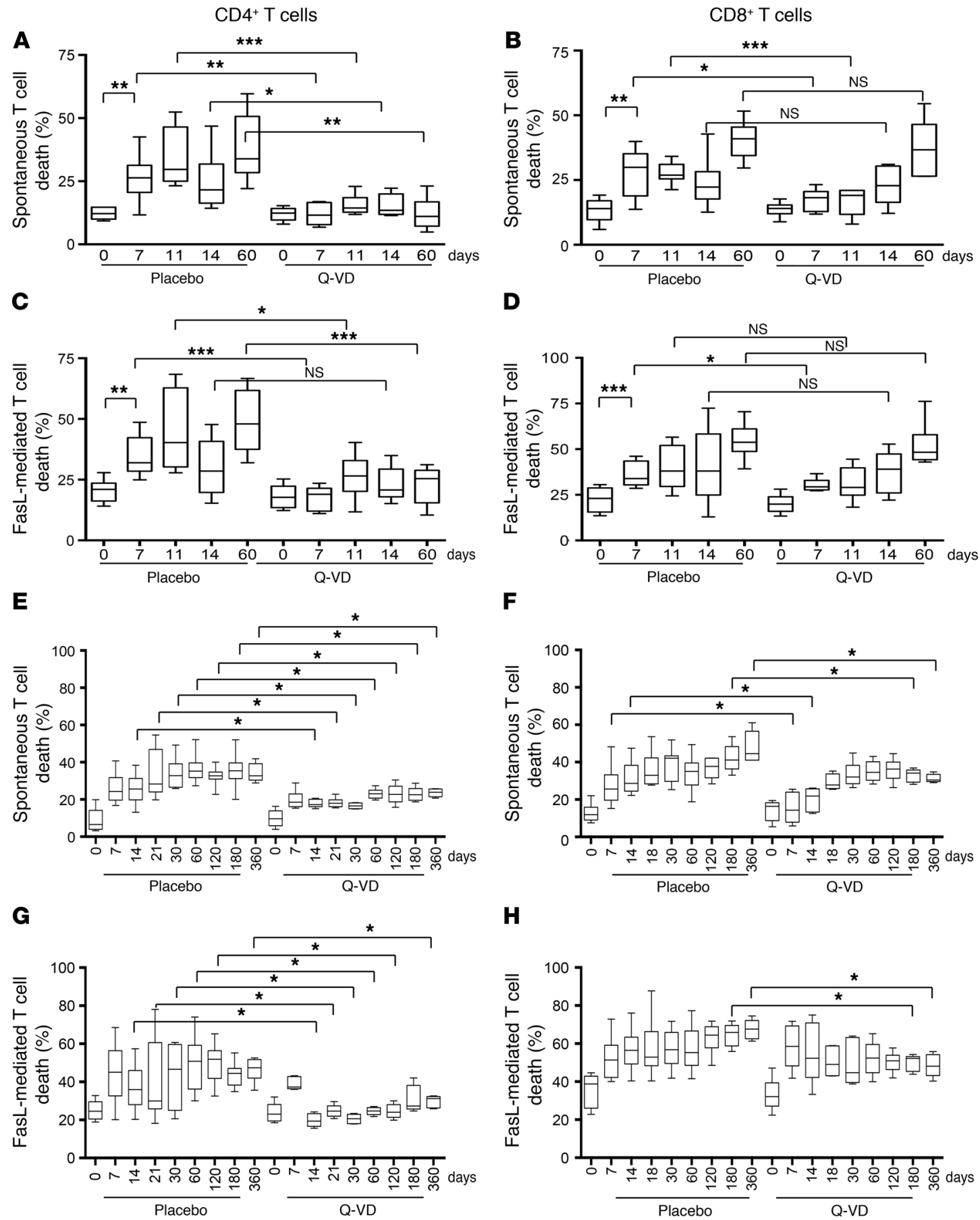

Figure 2. Q-VD-OPH treatment reduces T cell death in SIV-infected RMs. Percentages of dying CD3+CD4+ and CD3+CD8 ${ }^{+} T$ cells from peripheral $L N s$ (A-D) and blood (E-H) of either untreated (placebo, $n=12$ ) or Q-VD-OPH-treated RMs $(n=6)$ at different times after infection (A, B, E, and F). After overnight culture, spontaneous and (C, D, G, and $\mathbf{H})$ FasL-mediated T cell death was measured by flow cytometry using FITC-annexin V. Statistical differences were assessed using the Mann-Whitney $U$ test $\left({ }^{*} 0.01<P<0.05 ;{ }^{* *} 0.001<P<0.01 ;{ }^{* *} P<0.001\right)$. Prism was used to present the results in box-and-whisker plots showing the minimum and maximum of all the data.

cleavage, which is a prototypical substrate of effector caspases (Supplemental Figure 1A; supplemental material available online with this article; https://doi.org/10.1172/JCI95127DS1). Furthermore, Q-VD-OPH could also inhibit caspase-1 activity more efficiently than Z-VAD-FMK (Supplemental Figure 1B). These results demonstrated the superior efficacy of Q-VD-OPH in blocking caspase activation as compared with Z-VAD-FMK.
We then decided to analyze in detail the effect of Q-VD-OPH on $\mathrm{T}$ cell subsets. Immunophenotypical analysis conducted in fresh cells recovered from chronically SIV-infected RMs revealed that the preventive effect of Q-VD-OPH occurred mainly within the effector memory $\mathrm{CD} 4^{+} \mathrm{T}$ cell population (Tem, CD45RA ${ }^{-}$ CD62L $)(26.1 \% \pm 3.6 \%$ and $9.5 \% \pm 2.2 \%$ for control and Q-VD$\mathrm{OPH}$-treated cells, respectively) and to a lesser extent within 


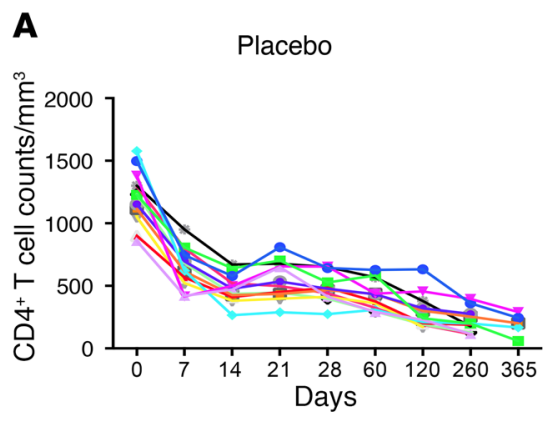

C
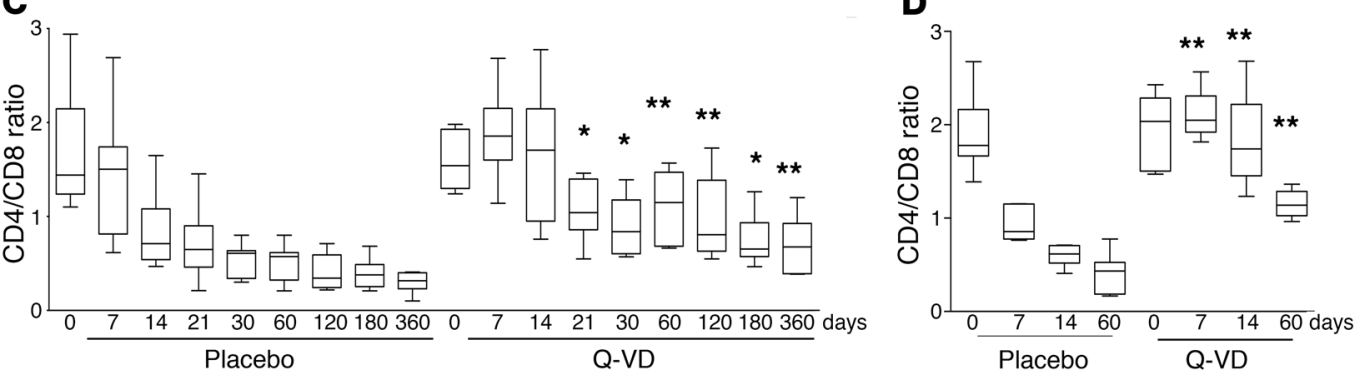

E

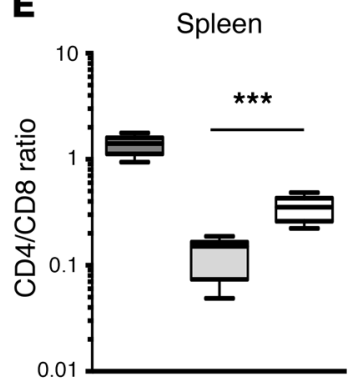

B

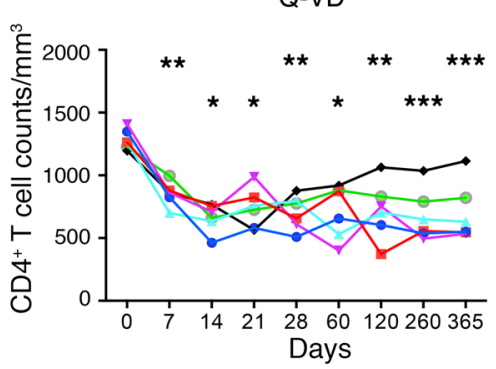

$D$

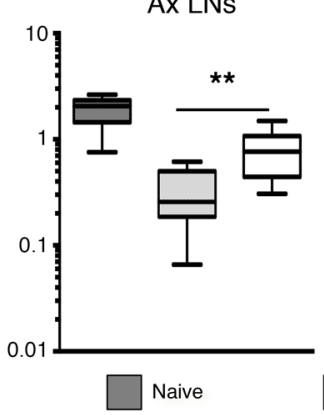

Ing LNs

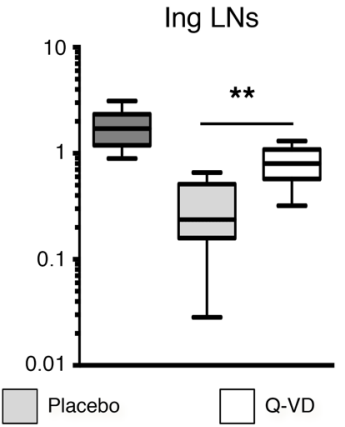

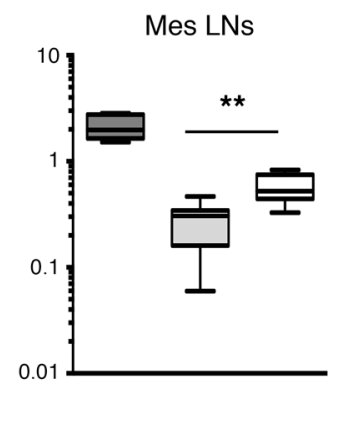

Figure 3. Q-VD-OPH preserves $\mathrm{T}$ cell homeostasis. $\mathrm{CD4}^{+} \mathrm{T}$ cell counts of peripheral blood of either (A) untreated (placebo, $n=12$ ) or (B) Q-VD-OPHtreated RMs $(n=6)$ at different times after infection. (C and D) $\mathrm{CD}^{+} / \mathrm{CD} 8^{+} \mathrm{T}$ cell ratio was calculated from (C) peripheral blood and (D) peripheral LNs (axillary and inguinal LNs). (E) $\mathrm{CD}^{+} / \mathrm{CD}^{+} \mathrm{T}$ cell ratio was calculated from spleen, axillary (Ax), inguinal (Ing), and mesenteric (Mes) LNs of healthy (Naive), of untreated (Placebo), and Q-VD-OPH-treated SIV-infected (Q-VD, white boxes) RMs. Statistical differences were assessed using the Mann-Whitney $U$ test comparing the 2 groups at each time point $\left({ }^{*} P<0.05 ;{ }^{* *} P<\right.$ 0.01 ; $\left.{ }^{* *} P<0.001\right)$. Prism was used to present the results in box-and-whisker plots showing the minimum and maximum of all the data. terminally differentiated $\mathrm{CD}^{+} \mathrm{T}$ cells $\left(\mathrm{CD} 45 \mathrm{RA}^{+} \mathrm{CD} 62 \mathrm{~L}-, 9.5 \% \pm\right.$ $2.2 \%$ and $4.5 \% \pm 1.5 \%$ ) (Figure $1 \mathrm{C}$ ). In addition, $\mathrm{Q}-\mathrm{VD}-\mathrm{OPH}$ protected $\mathrm{CD}^{+}$and $\mathrm{CD}^{+}{ }^{+} \mathrm{T}$ cells from (a) FasL-mediated cell death (Figure 1, D and E) and (b) AICD, which depends on the Fas/FasL pathway (Figure 1F). None of the other inhibitors that we tested afforded similar protection (data not shown). As a consequence of its antiapoptotic effect, the presence of Q-VD-OPH was associated with an increased proportion of proliferating $\mathrm{T}$ cells (CFSE dilution assay) after stimulation with concanavalin A (ConA) (Supplemental Figure 2).

Overall, these results demonstrated that Q-VD-OPH prevents ex vivo spontaneous and Fas-mediated $T$ cell death and enhances proliferation of cells isolated from chronically SIV-infected RMs.

In vivo administration of $Q-V D-O P H$ prevents $T$ cell death in SIV-infected RMs. To investigate the effect of Q-VD-OPH in vivo, we initially performed pharmacokinetic studies in uninfected animals. Q-VD-OPH was administered at 20 and $40 \mathrm{mg} / \mathrm{kg}$. These doses were chosen based on in vivo experiments performed in murine models $(54,55)$. The concentration of Q-VD-OPH was measured in the sera sampled at different time points after injection and in LNs recovered upon 4 hours of treatment. As expected, we found the higher concentrations of the compound, both in sera and LNs, and highest half-life in animals treated with the higher dose (Supplemental Figure 3, A and B). Moreover, we analyzed the levels of urea, transaminase (alanine aminotransferase [ALAT] and aspartate aminotransferase [ASAT]), and creatinine to assess liver and renal toxicity. No significant differences were found in any of the toxicity parameters evaluated between the sera of animals administered $20 \mathrm{mg} / \mathrm{kg} \mathrm{Q}-\mathrm{VD}-\mathrm{OPH}$ and those receiving vehicle alone (Supplemental Figure 3C). Among the animals treated with $40 \mathrm{mg} / \mathrm{kg}$ only $1 \mathrm{RM}$ (no. 9052) showed higher levels of urea, ALAT, and creatinine compared with the placebo-treated (DMSO) RMs (Supplemental Figure 3C). Thus, we selected the dose of 20 $\mathrm{mg} / \mathrm{kg}$ for the in vivo experiments included in this study.

Six RMs of Chinese origin were treated during the acute phase of SIVmac251 infection by intravenous injection of Q-VD-OPH (20 $\mathrm{mg} / \mathrm{kg}$ ), whereas vehicle was injected in the second group of RMs as a control (Supplemental Figure 4). The dosing regimen consisted of 5 Q-VD-OPH injections on days 5, 7, 9, 11, and 14 after infection, thus covering the peak of $T$ cell apoptosis observed during acute SIV infection (13-17). No statistically significant difference was observed in red blood cell and platelet counts or hemoglobin concentration between treated and untreated RMs, ruling out possible side effects of Q-VD-OPH injection during infection (Supplemental Figure 5). To monitor the in vivo levels of $\mathrm{T}$ cell death, we collected peripheral axillary and inguinal LNs from SIV-infected RMs on days 7, 11, 14, 
A

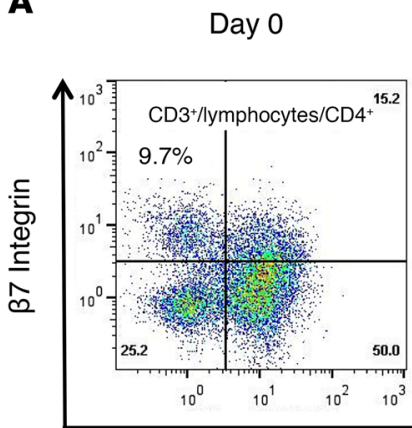

Day 14

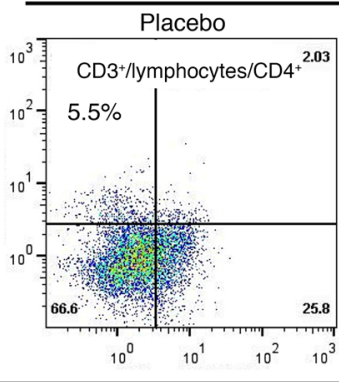

CD45RA
B

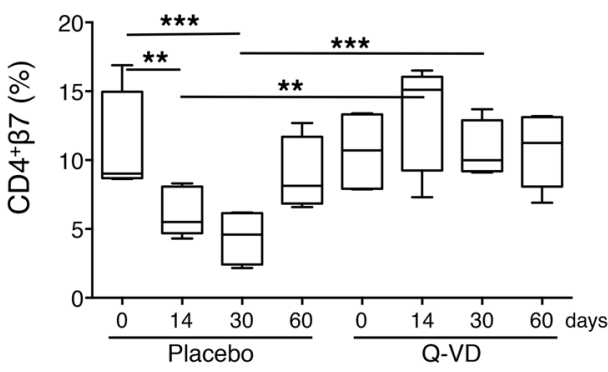

C

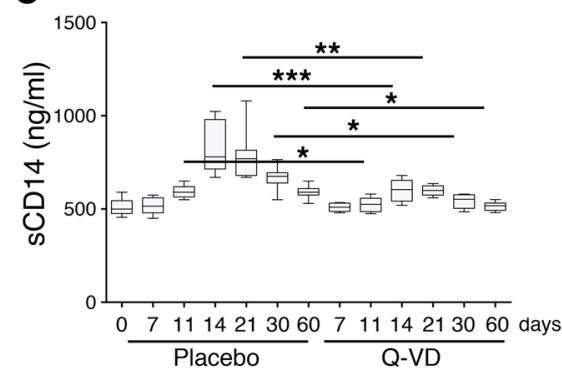

Figure 4. Q-VD-OPH prevents the depletion of $\beta 7^{\text {hi }} \mathrm{CD4}^{+} \mathrm{T}$ cells in SIV-infected RMs. (A) Representative flow cytometric analyses of coexpression of CD45RA and $\beta 7^{\text {hi integrin }}$ expression on $\mathrm{CD}^{+} \mathrm{CD}^{+} \mathrm{T}$ cells from peripheral blood of healthy RMs (day 0 ) and of either untreated (placebo) or Q-VD-OPH-treated RMs (Q-VD) on day 14. (B) Percentages of $\mathrm{CD}^{+} \mathrm{C}^{-}$ D4 ${ }^{+} C D 45 R A-\beta 7^{\text {hi }}$ T cell subset of placebo$(n=8)$ and Q-VD-OPH-treated RMs $(n=6)$ at different time point after infection. (C) sCD14 was measured in the sera by ELISA at different time points p.i. Statistical differences were assessed using the Mann-Whitney $U$ test $\left({ }^{*} 0.01<P<0.05 ;{ }^{* *} 0.001<P<0.01 ;{ }^{* * *} P<\right.$ $0.001)$. Prism was used to present the results in box-and-whisker plots showing the minimum and maximum of all the data. and 60 after infection. Indeed, the levels of apoptosis in peripheral LNs of RM are predictive of progression to $\operatorname{AIDS}(13,15,16)$. We first quantified the number of dying cells in vivo in LNs using a TUNEL assay as previously described $(13,16)$. We observed that the levels of TUNEL ${ }^{+}$cells were significantly lower in SIV-infected RMs treated with Q-VD-OPH as compared with untreated animals (Supplemental Figure 6, A and B). We then measured, in the sera of treated and control RMs, the levels of IL-18, a proinflammatory cytokine belonging to the IL-1 superfamily whose maturation is dependent on caspase activation $(56,57)$ and that was previously reported to be increased during the acute phase of SIV infection in RMs $(58,59)$. We found that in Q-VD-OPH-treated RMs, IL-18 levels were significantly decreased on postinfection (p.i.) days 11 and 14 compared with those in control SIV-infected RMs (Supplemental Figure 7A), thus suggesting in vivo inhibition of caspase activation.

We then quantified ex vivo the levels of spontaneous and FasL-mediated apoptosis of $\mathrm{CD} 4^{+} \mathrm{T}$ cells isolated from LNs. Our data demonstrated lower levels of $\mathrm{CD}^{+} \mathrm{T}$ cell death from LNs isolated from RMs treated with Q-VD-OPH compared with untreated RMs. This protective effect was observed on days 7, 11, and 14 after infection (Figure 2, A and C). Of note, however, the level of CD4 ${ }^{+} \mathrm{T}$ cell death remained significantly lower in Q-VD-OPH-treated RMs as compared with controls on day 60 after infection, i.e., more than 6 weeks after the interruption of treatment. This long-term effect of Q-VD-OPH administration was confirmed by the observation of lower levels of $\mathrm{CD} 4{ }^{+} \mathrm{T}$ cell death in the peripheral blood up to 1 year after treatment (Figure 2, E and G). Furthermore, we also observed that the formation of the cleaved form of the effector caspase-3, as measured by Western blotting, was prevented in $\mathrm{CD}^{+} \mathrm{T}$ cells isolated from Q-VD-OPH-treated RMs as compared with control animals (Supplemental Figure 8). This difference was not related to a difference in CD95 expression in CD4 ${ }^{+} \mathrm{T}$ cells (Supplemental Figure 9). FasL, the counterpart of CD95, has been reported to increase during $\operatorname{HIV}(25,60)$ and SIV infections $(14,61)$. When performing analysis on $\mathrm{LN}$-derived $\mathrm{CD}^{+} \mathrm{T}$ cells, we found that, as in $\mathrm{CD}^{+} \mathrm{T}$ cells, the levels of spontaneous and FasL-mediated apoptosis were lower in Q-VD-OPH-treated SIV-infected RMs as compared with control animals during the acute phase of infection (Figure 2, B and D). However, in contrast to what we observed for LN-derived $\mathrm{CD}^{+} \mathrm{T}$ cells, the effect of $\mathrm{Q}-\mathrm{VD}-\mathrm{OPH}$ on the spontaneous and FasL-mediated apoptosis of $\mathrm{LN}$-derived $\mathrm{CD}^{+} \mathrm{T}$ cells was limited to the period of treatment, while the preventive antiapoptotic effect on blood-derived $\mathrm{CD}^{+} \mathrm{T}$ cells was smaller than that observed for $\mathrm{CD}^{+}{ }^{+} \mathrm{T}$ cells (Figure $2, \mathrm{~F}$ and $\mathrm{H}$ ).

As the level of IL-18, which is a potent inducer of FasL $(62,63)$, is reduced in Q-VD-OPH-treated RMs, we quantified FasL in the sera. We found that levels of FasL were reduced in Q-VD-OPHtreated SIV-infected RMs as compared with control SIV-infected animals and that this effect lasted after the cessation of treatment (Supplemental Figure 7B).

Together, these results demonstrated that treatment with $\mathrm{Q}-\mathrm{VD}-\mathrm{OPH}$ reduced the levels of $\mathrm{CD}^{+} \mathrm{T}$ cell death during the acute phase but also after treatment interruption.

$Q-V D-O P H$ treatment prevents $C D 4^{+} T$ cell depletion. We then monitored $\mathrm{CD} 4^{+} \mathrm{T}$ cell depletion in treated compared with untreated RMs. The in vivo Q-VD-OPH treatment resulted in a higher $\mathrm{CD} 4^{+} \mathrm{T}$ cell count and higher $\mathrm{CD} 4 / \mathrm{CD} 8$ ratios in peripheral blood throughout infection (Figure 3, A-C) and higher CD4/CD8 ratio in LNs (Figure 3D) as compared with control animals. On the sacrifice day, we found that the CD4/CD8 ratio in spleen and axillary, inguinal, and mesenteric LNs were also higher in Q-VDOPH-treated SIV-infected RMs compared with the placebo group (Figure 3E) despite a longer duration of SIV. Since high expression of $\beta 7$ on $C D 4^{+} \mathrm{T}$ cells in peripheral blood is a useful surrogate for estimating intestinal CD $4^{+} \mathrm{T}$ cell loss (64), we also assessed during the acute phase the dynamics of $\mathrm{CD}^{+} \mathrm{T}$ cells coexpressing 

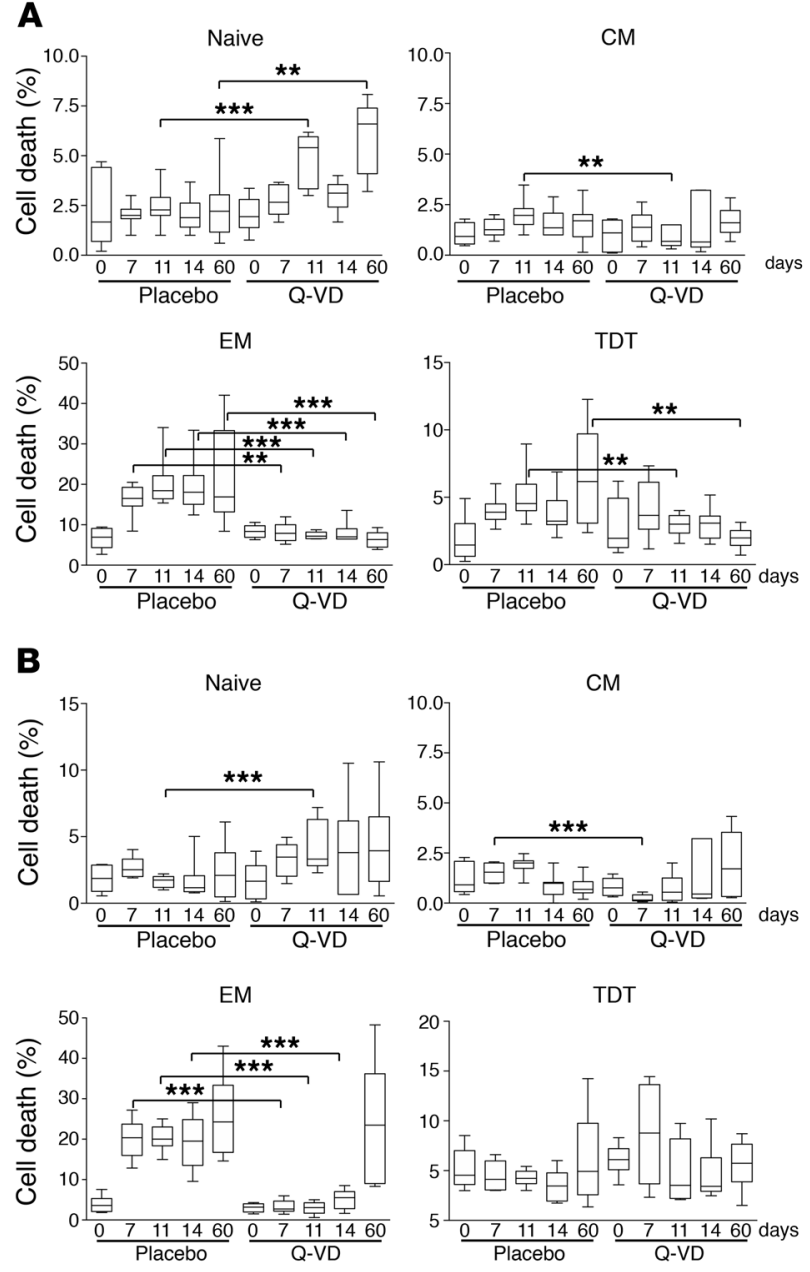

CD45RA and $\beta 7^{\text {hi }}$. Our results showed the early loss of the circulating $\beta 7^{\text {hi }} \mathrm{CD}^{+} \mathrm{T}$ cell population in SIV-infected RMs. In contrast, such loss was not observed in Q-VD-OPH-treated RMs (Figure 4, $A$ and B). Furthermore, we measured the levels of soluble CD14 (sCD14), which is a well-established marker of microbial translocation associated with the depletion of $\mathrm{CD}^{+}{ }^{+} \mathrm{T}$ cells in the intestine and with clinical end points (65-69). We found that sCD14 was significantly decreased in Q-VD-OPH-treated SIV-infected RMs as compared with control animals (Figure $4 \mathrm{C}$ ).

Because $\mathrm{CD}^{+} / \mathrm{CD}^{+} \mathrm{T}$ cell ratio is considered a strong marker of disease progression to AIDS (70), our results demonstrated that treatment with $\mathrm{Q}-\mathrm{VD}-\mathrm{OPH}$ afforded long-term protection preserving $\mathrm{CD}^{+} \mathrm{T}$ cell homeostasis.

$Q-V D-O P H$ treatment prevents the loss of memory $T$ cells and decreases immune activation. To better understand the repopulation of $\mathrm{CD}^{+} \mathrm{T}$ cells, and because the progressive loss of central and effector memory $\mathrm{CD}^{+} \mathrm{T}$ cells is associated with AIDS pathogenesis $(13,15,71-76)$, we next investigated, in our cohort of SIV-infected RMs, the effect of Q-VD-OPH on the dynamics of $\mathrm{CD}_{4}^{+} \mathrm{T}$ cell subsets. We found that $\mathrm{CD} 4^{+} \mathrm{Tem}$ (CD45RA-CD62L-) cells from LNs of Q-VD-OPH-treated SIV-infected RMs were less prone to die as compared with LN-derived $\mathrm{CD}^{+}$Tem cells of nontreated SIV-infected RMs during the acute phase of infection and up to 60 days after
Figure 5. Q-VD-OPH treatment reduces memory $T$ cell death in SIV-infected RMs. Dying $\mathrm{CD}^{+}(\mathbf{A})$ and $\mathrm{CD} 8^{+}$(B) T cell subsets (naive, CD45RA+CD62L'; Tcm, CD45RA-CD62L'; Tem, CD45RA-CD62L-; TDT, CD45RA+CD62L-) of either untreated (placebo, $n=12$ ) or Q-VD-OPH-treated RMs (Q-VD, $n=6$ ) were quantified after overnight culture by flow cytometry using annexin $\mathrm{V}$ (spontaneous T cell death). Statistical differences were assessed using the Mann-Whitney $U$ test $\left({ }^{*} 0.01<P<0.05\right.$; ${ }^{* *} 0.001<P<0.01$; $\left.{ }^{* *} P<0.001\right)$. Prism was used to present the results in box-and-whisker plots showing the minimum and maximum of all the data.

termination of the treatment (Figure 5A). A similar pattern of reduced spontaneous cell death, although to a lesser extent, was observed in both central memory (Tcm, CD45RA-CD62 $\mathrm{L}^{+}$) and terminally differentiated $\left(\mathrm{CD} 45 \mathrm{RA}^{+} \mathrm{CD} 62 \mathrm{~L}^{-}\right) \mathrm{CD}^{+} \mathrm{T}$ cells (Figure $5 \mathrm{~A}$ ). Although the death of naive $\mathrm{CD} 4^{+} \mathrm{T}$ cells was low, we observed a slight increase in naive $\mathrm{CD} 4^{+} \mathrm{T}$ cells from LNs of $\mathrm{Q}-\mathrm{VD}-\mathrm{OPH}$-treated SIV-infected RMs. Consistent with this protective effect of Q-VD-OPH, the percentage of Tem cells among the total LN T cell pool was greater in treated SIV-infected RMs as compared with control animals (Figure 5A). Of note, CD $4^{+}$ Tcm cells, which are also progressively depleted during pathogenic SIV infection, were similarly preserved in Q-VD-OPHtreated RMs as compared with controls (Figure 6A). The distribution of the different $\mathrm{T}$ cell subsets among the pool of $\mathrm{CD} 4^{+} \mathrm{T}$ cells (Figure 6C) illustrates the selective preservation of specific $\mathrm{CD}^{+}{ }^{+} \mathrm{Tcm}$ cell subsets in Q-VD-OPH-treated RMs.

Furthermore, Q-VD-OPH treatment was associated with a transient decrease in $\mathrm{CD}^{+}$Tem and Tcm cell death in LNs of SIV-infected RMs (Figure 5B) and a slight increase in levels of naive $\mathrm{CD}^{+} \mathrm{T}$ cells on day 11 . As a consequence, $\mathrm{Q}-\mathrm{VD}-\mathrm{OPH}-$ treated RMs showed a higher percentage of LN-based CD8 ${ }^{+}$ Tcm cells as compared with control animals, which exhibited, as expected, higher percentages of $\mathrm{LN}$-based $\mathrm{CD} 8^{+} \mathrm{Tem}$ and terminally differentiated $\mathrm{T}$ cells (Figure $5 \mathrm{~B}$ ). As shown in Figure 6, B and $\mathrm{D}$, the distribution kinetics of the distinct $\mathrm{CD} 8^{+} \mathrm{T}$ cell subsets clearly illustrates the differences in the balance of terminally differentiated $\mathrm{T}$ cells and Tcm cells in Q-VD-OPH-treated and untreated RMs. We then assessed the levels of immune activation of $\mathrm{LN} \mathrm{CD}^{+} \mathrm{T}$ cells and found that $\mathrm{Q}-\mathrm{VD}-\mathrm{OPH}$ treatment was associated with decreased levels of $\mathrm{CD} 8^{+} \mathrm{T}$ cell activation, as measured by the frequency of $\mathrm{CD} 8^{+} \mathrm{T}$ cells expressing the activation markers HLA-DR and Ki-67, as compared with untreated controls (Supplemental Figure 10).

Together, these results suggest that Q-VD-OPH treatment improved the overall homeostasis of memory $\mathrm{T}$ cells and reduced the level of immune activation during the chronic phase of SIV infection.

$Q-V D-O P H$ treatment induces SIV-specific $C D 4^{+} T$ effector cells. To investigate the impact of Q-VD-OPH on SIV-specific CD $4^{+} \mathrm{T}$ cell immune response, we next evaluated the expression of IFN- $\gamma$ and TNF- $\alpha$ by intracellular cytokine staining (ICS) after in vitro HIV-2 antigen stimulation (Supplemental Figure 10). The use of such crude antigen preparation, as opposed to individual peptides, has been validated in our laboratory as well as others as a tool to best detect SIV-specific CD $4^{+} \mathrm{T}$ cell responses in the setting of the broad MHC genetic polymorphisms present in RMs $(13,77,78)$. We found that at 2 weeks after infection, the percentage of SIVspecific $\mathrm{CD}^{+} \mathrm{T}$ cells expressing IFN- $\gamma$ and TNF- $\alpha$ was approx- 
A
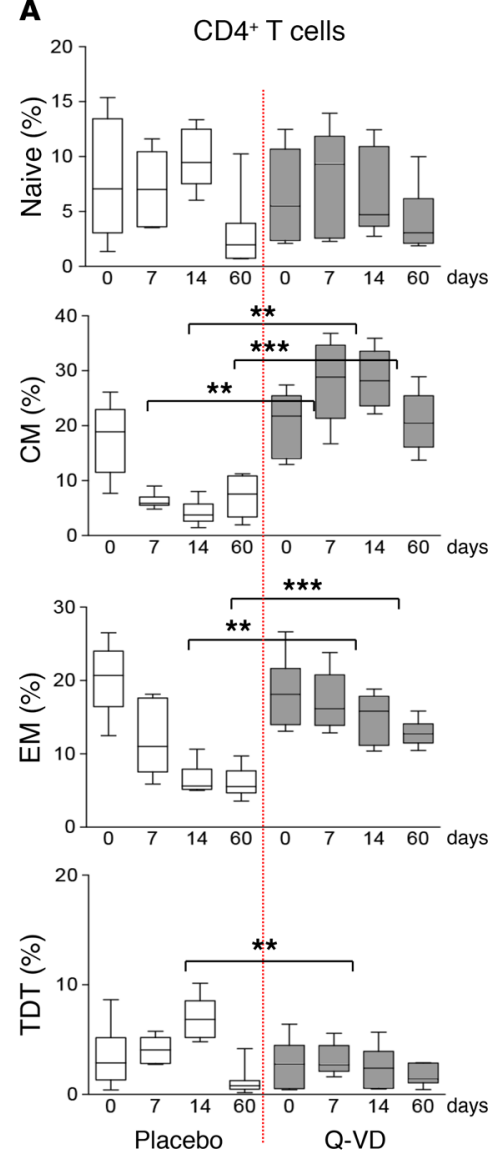

$c$

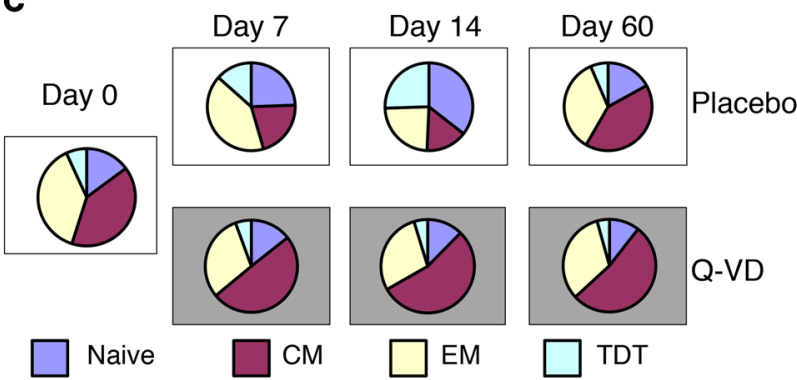

D

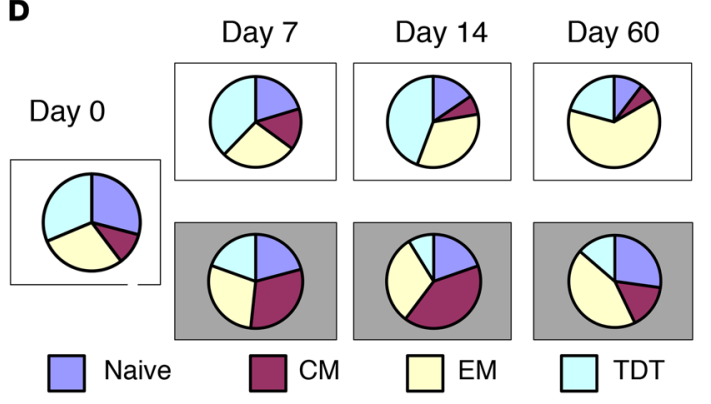

Figure 6. Q-VD-OPH inhibits in vivo the depletion of memory T cells in SIV-infected RMs. Percentages of (A) $\mathrm{CD}^{+} \mathrm{CD}^{+}$and (B) $\mathrm{CD}^{+} \mathrm{CD}^{+} \mathrm{T}$ cell subsets (naive, CD45RA ${ }^{+} \mathrm{CD} 62 \mathrm{~L}^{+} ; \mathrm{Tcm}$, CD45RA-CD62L'; Tem, CD45RA-CD62L'; TDT, CD45RA+CD62L') among total T cells from peripheral LNs of either untreated (placebo, $n=12$ ) or Q-VD-OPH-treated RMs (Q-VD, $n=6$ ) at different time points after infection. T cell subsets were analyzed by flow cytometry. The pie charts represent the distribution of cell subsets among either (C) $C D 3^{+} C D 4^{+}$or $(D) C D 3^{+} C D 8^{+} T$ cell populations. Statistical differences were assessed using the Mann-Whitney $U$ test $\left(^{*} 0.01\right.$ $<P<0.05 ;{ }^{* *} 0.001<P<0.01 ;{ }^{* *} P<0.001$ ). Prism was used to present the results in boxand-whisker plots showing the minimum and maximum of all the data. imately 10-fold higher in Q-VD-OPH-treated than control RMs (Supplemental Figure 11A). In vitro T cell proliferation, as measured by thymidine incorporation after 5 days of culture, confirmed the increased ability of $\mathrm{CD}^{+}{ }^{+} \mathrm{T}$ cells from Q-VD-OPH-treated SIVinfected RMs to respond to HIV-2 antigens as compared with those isolated from control animals (Supplemental Figure 11B).

To determine the effect of Q-VD-OPH on the expression of cytotoxic molecules, we next analyzed the expression of perforin, granzyme $\mathrm{B}$, and granulysin in purified $\mathrm{T}$ cells by Western blotting (Supplemental Figure 12). Purified $\mathrm{CD} 8^{+} \mathrm{T}$ cells from untreated SIVinfected RMs showed reduced expression of perforin and granulysin molecules as compared with those from healthy animals, with no full restoration in Q-VD-OPHtreated SIV-infected RMs (Supplemental Figure 12A). In 1 SIV-infected RM (lane 4), a higher level of granzyme $\mathrm{B}$ was found to be associated with the lowest level of perforin, which is essential for granzyme B-mediated killing. A growing body of evidence suggests that $\mathrm{CD} 4^{+}$ T cells also can themselves display potent antiviral activity by killing virus-infected cells including cytomegalovirus (79), influenza (80), Friend virus (81), Epstein-Barr virus (82), murine poxvirus (83), and BK polyomavirus (84). In HIV-infected individuals, the presence of cytolytic HIV-specific $\mathrm{CD} 4^{+} \mathrm{T}$ cells has been associated with control of virus replication and delayed disease progression (85-89). Interestingly we observed that the expression of perforin, granzyme B, and granulysin in $\mathrm{CD}^{+} \mathrm{T}$ cells was preserved or even augmented in chronically Q-VD-OPH-treated SIV-infected RMs compared with untreated SIV-infected RMs (Supplemental Figure 12B). We then assessed the proportion of cytotoxic $\mathrm{CD} 4^{+} \mathrm{T}$ cells by analyzing the expression of perforin, granzyme $\mathrm{B}$, and granulysin by flow cytometry. Our results demonstrated that $\mathrm{CD} 4^{+} \mathrm{T}$ cells from Q-VD-OPH-treated SIV-infected RMs expressed higher levels of perforin, granzyme $\mathrm{B}$, and granulysin than those from naive RMs (Figure 7, A and B). Similarly, the frequency and the numbers of $\mathrm{CD} 4^{+} \mathrm{T}$ cells expressing TIA1, the cytotoxic granule-associated protein, are preserved under treatment compared with control animals in chronically Q-VD-OPH-treated SIV-infected RMs (Figure 7, C and D).

Together, these findings indicated that treatment with Q-VD-OPH resulted in more robust SIV-specific $\mathrm{CD}^{+} \mathrm{T}$ cell responses, associated with higher levels of total cytotoxic $\mathrm{CD} 4^{+} \mathrm{T}$ cells.

$Q-V D-O P H$ reduces viral replication and delays progression to AIDS. The observations that $\mathrm{Q}-\mathrm{VD}-\mathrm{OPH}$ treatment of SIV-infected RMs improves the overall homeostasis of $\mathrm{CD}^{+} \mathrm{T}$ cells prompted us to investigate the impact of Q-VD-OPH treatment on the levels of SIV replication. We found that the levels of viral replication were significantly lower in SIV-infected Q-VD-OPHtreated RMs as compared with control animals (Figure 
A

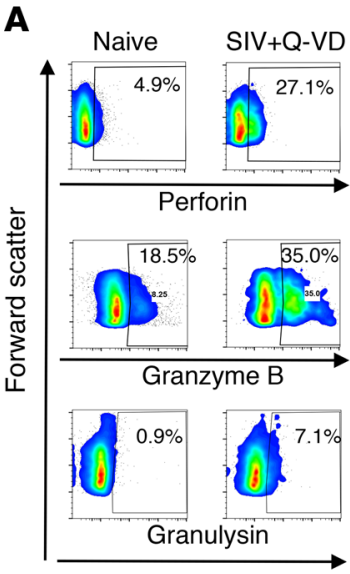

B

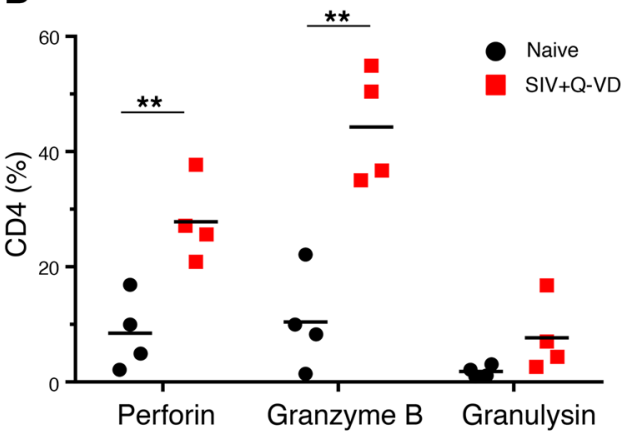

C

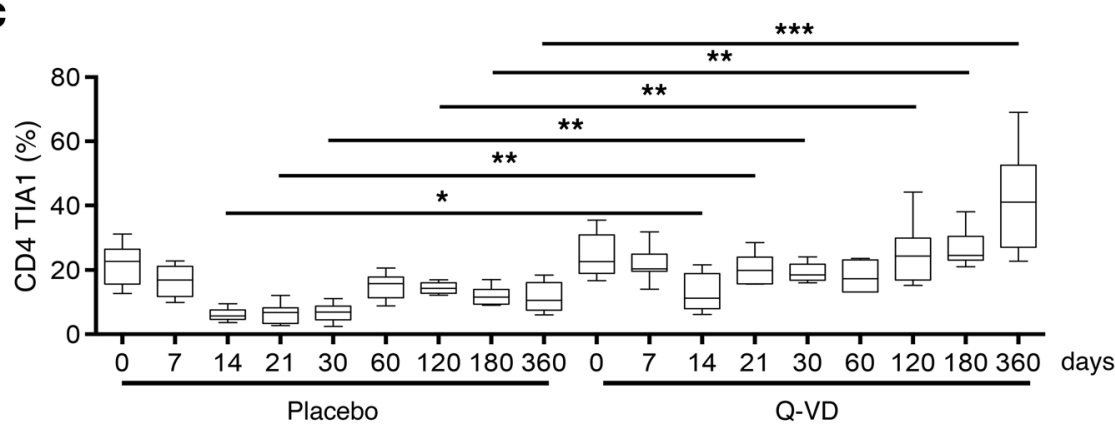

D

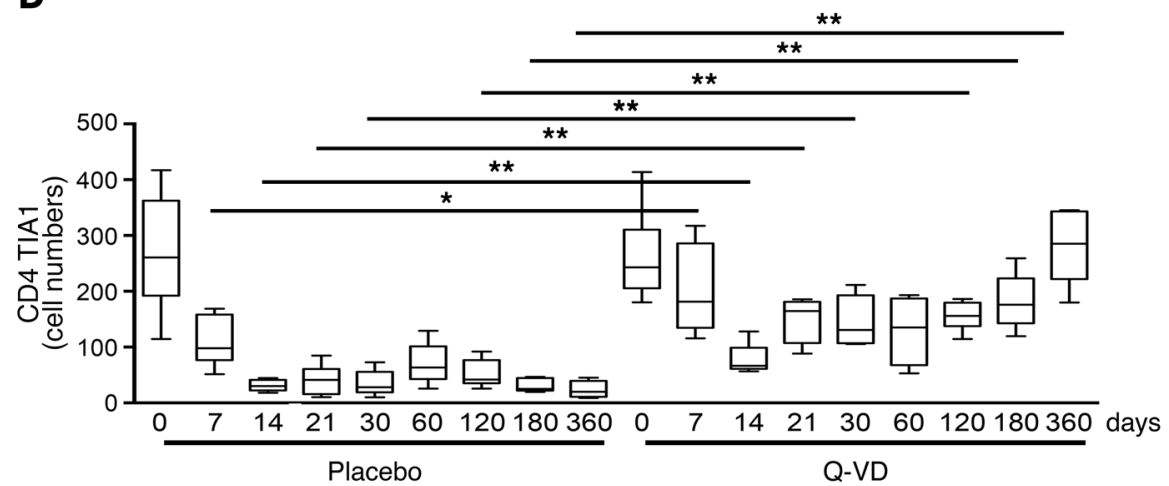

Figure 7. Expression of cytolytic molecules in $\mathrm{CD4}^{+} \mathrm{T}$ cells of SIV-infected RMs. (A) Flow cytometric analyses of perforin, granzyme B, and granulysin expressions in CD4 ${ }^{+} \mathrm{T}$ cells from peripheral blood of 1 representative healthy RM (naive) and 1 SIV-infected RM treated with Q-VD-OPH (SIV+Q-VD). (B) Histogram shows the percentage of $\mathrm{CD}^{+} \mathrm{T}$ cells expressing perforin, granzyme B, and granulysin at day 120 (each dot plot represents 1 individual). (C) Percentages and (D) cell numbers of $\mathrm{CD4}{ }^{+} \mathrm{T}$ cells expressing TIA1 in either untreated (placebo, $n=6$ ) or Q-VD-OPHtreated RMs $(n=6)$ on days $0,7,14,21,30,60$, 120,180 , and 360 after infection. Statistical differences were assessed using the MannWhitney $U$ test $\left({ }^{*} 0.01<P<0.05 ;{ }^{* *} 0.001<P\right.$ $\left.<0.01 ;{ }^{* *} P<0.001\right)$. In B-D, values above data represent $P$ values. Prism was used to present the results in box-and-whisker plots showing the minimum and maximum of all the data.
8A), with an AUC of viral load that was significantly lower during the acute phase of SIV infection (i.e., week 1 until week 4 , AUC, $P=$ 0.01 ) (Figure 5B). Interestingly, viral load continued to decline and remained low throughout the chronic phase of infection (Figure 8, $\mathrm{A}$ and $\mathrm{B}$ ) despite the short course of treatment (the last Q-VD-OPH injection was administrated on day 14 p.i.). We next measured the levels of cell-associated SIV DNA in blood CD $4^{+} \mathrm{T}$ cells and found lower levels in Q-VD-OPH-treated SIV-infected RMs as compared with control animals at all time points after treatment (Figure $8 \mathrm{C}$ ). Importantly, and consistent with the presence of lower levels of virus replication, none of the Q-VD-OPH-treated SIVinfected RMs presented clinical signs of AIDS (Figure 8D), whereas 8 of 12 animals in the control group developed a wasting syndrome - including repetitive diarrhea, weight loss (greater than $10 \%$ ), and anorexia - associated with a decline in $\mathrm{CD}^{+} \mathrm{T}$ cell counts, resulting in the euthanasia of RMs in less than 1 year after the initial infection.
Together, these results demonstrate that treatment with Q-VD-OPH during the acute phase of SIV infection in RMs resulted in long-term control of viral replication and delayed disease progression.

\section{Discussion}

In this study, we have shown that Q-VD-OPH may represent a novel compound to be explored as a potential treatment for HIV/ SIV infection due to its strong anti-caspase effect in vitro and in vivo, which results in better immunological, virological, and clinical outcomes of SIV infection in RMs. We wish to point out that while many studies in vivo and in vitro have revealed a clear association between HIV/SIV disease progression and the levels of $\mathrm{T}$ cell death, the current study is the first to our knowledge showing, in a highly relevant animal model, that a pharmacological inhibitor of caspase has a significant impact on the pathogenicity of an AIDS virus infection. 
A
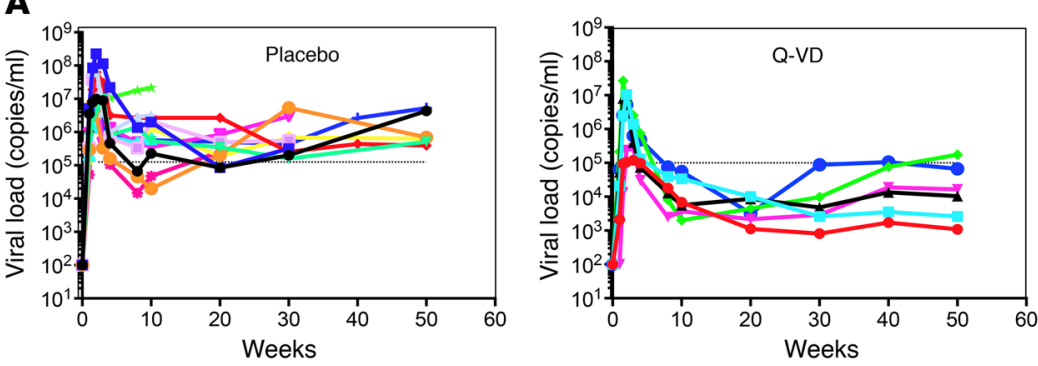

B

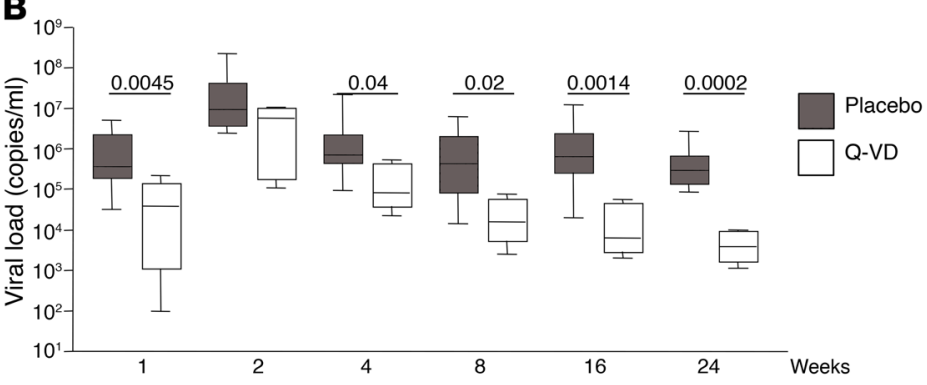

C

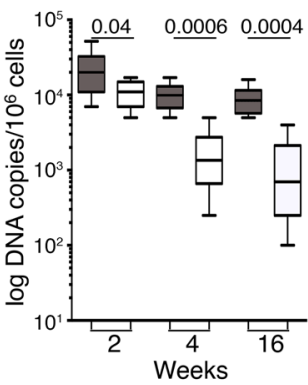

D

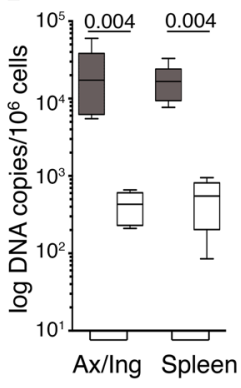

E

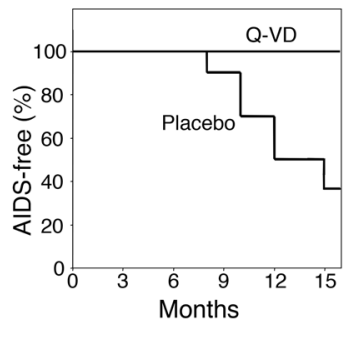

Figure 8. Viral dynamics during primary SIV infection. (A) Kinetic analysis of viremia in nontreated RMs (Placebo; $n=$ 12) and Q-VD-OPH-treated RMs $(n=6)$. (B) Comparison of nontreated (placebo) and Q-VD-OPH-treated RMs. AUCs were significantly different $(P=0.01)$. (C) Frequency of SIV-DNA ${ }^{+} C D 4^{+} T$ cells in blood of SIV-infected RMs treated without (placebo, $n=10$, filled boxes) or with Q-VD-OPH ( $n$ $=6$, white boxes). (D) Frequency of SIV-DNA ${ }^{+}$CD4 ${ }^{+} \mathrm{T}$ cells in lymphoid tissues (axillary and inguinal LNs, and spleen at the day of sacrifice) of SIV-infected RMs treated without (placebo, $n=6$, filled boxes) or with Q-VD-OPH ( $n=6$, white boxes). (E) Percentage of RMs remaining alive after infection without developing an AIDS wasting syndrome (AIDS-free). Statistical analysis was assessed using the Mann-Whitney $U$ test. Prism was used to present the results in box-and-whisker plots showing the minimum and maximum of all the data.
The main results of this study are that early and transient Q-VD-OPH therapy (a) prevents the activation of caspases and the occurrence of T cell death; (b) favors the preservation of both Tcm and Tem cells, which is associated with stronger SIV-specific CD $4^{+}$ $\mathrm{T}$ cell responses; $(\mathrm{c})$ reduces $\mathrm{CD} 4^{+} \mathrm{T}$ cell depletion in the gut and immune activation; (d) reduces the levels of virus replication; and (e) delays the development of AIDS.

Recent studies suggest that early treatment initiation during primary HIV-1 infection may reduce viral replication (90), limit viral reservoirs (91), and preserve the antiviral host immune response (92, 93). Recently, the administration of a recombinant rhesus anti- $\alpha 4 \beta 7$ $\mathrm{mAb}$, which maintains normal CD4 ${ }^{+} \mathrm{T}$ cell counts in the blood and in gut-associated lymphoid tissue (GALT) was found to control viremia without the need for further therapy (94). However, the mechanisms associated with this long-term protection remain poorly understood. Our results demonstrated that treatment with $\mathrm{Q}-\mathrm{VD}-\mathrm{OPH}$ during the acute phase of SIV infection is associated with a persistent expansion of specific memory $\mathrm{CD} 4^{+} \mathrm{T}$ cells. Because at the same time we observed lower viremia, we cannot exclude that this process participates in the reconstitution of these immune cells, whether these immune cells contribute to virologic control, or even both. Of note, our observation is consistent with the fact that depletion of $\mathrm{CD} 4^{+}$ $\mathrm{T}$ cells prior to SIV infection of RMs is associated with loss of virus control, rapid disease progression, and neurodegenerative diseases (95). We have not analyzed in detail all lymphoid or non-lymphoid cell types reported to be abnormally primed to undergo death during HIV/SIV infection (61, 96-99), due to the relatively limited availability of samples and tissues; however, our observation that the pool of $\mathrm{CD} 4^{+} \mathrm{T}$ cells expressing $\beta 7^{\mathrm{hi}}(64)$ is preserved during the acute phase and associated with lower levels of sCD14 in Q-VD-OPH-treated SIV-infected RMs suggests that this treatment was associated with a preserved intestinal $\mathrm{CD} 4^{+} \mathrm{T}$ cell pool and integrity of the epithelial barrier of the gastrointestinal tract (65-67). Interestingly, at the time of necropsy, the ratio of CD4 to CD8 in peripheral LNs as well as the spleen and mesenteric LNs was higher in Q-VD-OPH-treated SIV-infected RMs as compared with placebo-treated controls, thus indicating a global preservation of $\mathrm{T}$ cell homeostasis. In this study, we have shown for the first time to our knowledge that a strong, selective blockade of caspase activation may have a significant beneficial impact on the immunological, virological, and clinical course of SIV infection. Importantly, although Q-VD-OPH was injected only during the acute phase of infection, the beneficial effect persisted throughout the chronic phase. Interesting work published by Whitney et al. (100) demonstrates that blocking viral replication during the acute phase with antiretroviral treatment (ART) is not sufficient to provide protection once ART is interrupted. Thus, we speculate that a dual strategy combining ART with Q-VD-OPH would contribute to controlling viral rebound. In this sense, it has been shown that a vaccination based on the use of Ad26/MVA with TLR improves virologic control and delays viral rebound following discontinuation 
of ART in SIV-infected RMs (101). Therefore, a dual strategy aiming to target both the virus and the host immune system leading to the induction of robust HIV-specific immune responses may lead to better control and an HIV cure.

In this study, we found that the control of viral replication mediated by Q-VD-OPH is not dependent on the presence of increased numbers of Tem and activated $\mathrm{CD} 8^{+} \mathrm{T}$ cells. Our results indicated that treatment with $\mathrm{Q}-\mathrm{VD}-\mathrm{OPH}$ was associated with lower levels of $\mathrm{CD}^{+} \mathrm{T}$ cell activation, which represent a known predictive marker of disease progression in RMs of Chinese origin $(13,16,17,75,102-104)$. This lower level of immune activation is consistent with lower viral load and cell-associated SIV DNA. However, $\mathrm{CD} 8^{+} \mathrm{T}$ cells remain sensitive to death during the chronic phase of infection, dissociating $\mathrm{CD}^{+}$and $\mathrm{CD}^{+} \mathrm{T}$ cell responses. We and others have shown that non-pathogenic models of lentiviral infections displayed some $\operatorname{CD}^{+}(7,8,105)$, but not $\mathrm{CD}^{+}$, $\mathrm{T}$ cell apoptosis, indicating different processes.

Our results show that Q-VD-OPH treatment during the acute phase of SIV infection is associated with higher levels of $\mathrm{CD} 4^{+} \mathrm{T}$ cells expressing cytotoxic molecules including perforin, granzyme $\mathrm{B}$, and granulysin than $\mathrm{CD} 4^{+} \mathrm{T}$ cells of untreated SIV-infected or even healthy, uninfected RMs. It was previously reported that SIV-specific $\mathrm{CD} 4^{+} \mathrm{T}$ cells in SIV $\Delta$ nef-vaccinated animals express perforin and possess direct cytolytic activity (106). It has been also reported that cytotoxic $\mathrm{CD} 4^{+} \mathrm{T}$ cells are associated with early viral load set point (107). Furthermore, individuals who controlled viral replication had a significant expansion of HIV-specific $\mathrm{CD}^{+} \mathrm{T}$ cells compared with individuals who progressed to higher viral set points (89). Together, these studies support a role for $\mathrm{CD}^{+}$cytotoxic $\mathrm{T}$ lymphocytes (CTLs) in controlling early viral replication and contributing to delayed disease progression. The limitations of current highly active ART include the incidence of drug resistance observed in patients, issues of drug adherence, and newly acquired infections. Drug resistance represents a key aspect of treatment failure (108). Therefore, a possible beneficial effect of reinforcing the immune response and controlling the infection should be countering the emergence of resistance through the generation and recruitment of effector $\mathrm{CD} 4^{+} \mathrm{T}$ cells.

We and others have previously demonstrated that in HIVinfected individuals, caspases are activated through FasL, thus leading to apoptosis $(9,10,21)$, and that the activation of caspase occurs in bystander $\mathrm{CD}^{+} \mathrm{T}$ cells $(21,23,52)$. In particular, caspase- 1 activation is associated with increased inflammation in myeloid cells (109-112). Thus, in monocytes/macrophages, which are the major source of IL-18, inflammasome activation and secretion of mature IL-18 require the activation of caspase- $1(56,57)$. In this context, our finding of decreased amounts of IL-18 in Q-VD$\mathrm{OPH}$-treated RMs indicated that this compound targets caspase-1 in vivo, consistent with the in vitro data (Supplemental Figure $1 \mathrm{~B})$, and that $\mathrm{Q}-\mathrm{VD}-\mathrm{OPH}$ modulates inflammasome activity in monocytes/macrophages. As such, Q-VD-OPH appears to act as a potent in vivo modulator of pyroptosis $(21,23,52)$. The decrease in IL-18 and FasL associated with Q-VD-OPH treatment during the acute phase of SIV infection may also have an indirect impact on the levels of $\mathrm{CD}^{+} \mathrm{T}$ cell apoptosis, as anti-FasL treatment during the initial stages of SIV infection has been reported to preserve $\mathrm{T}$ cell homeostasis and sustain cell-mediated immunity to SIV (113).
Therefore, we propose that a key immunological effect of Q-VD$\mathrm{OPH}$ is the relative preservation of $\mathrm{CD} 4^{+}$memory $\mathrm{T}$ cell homeostasis, with increased activity of SIV-specific effector $\mathrm{CD} 4^{+} \mathrm{T}$ cells.

In conclusion, the current study provides evidence that the administration of the anti-caspase agent Q-VD-OPH, in the absence of ART, during the acute phase of SIV infection in RMs is associated with a number of beneficial effects that positively influence the immunological, virological, and clinical course of the infection. We believe that this molecule may represent a novel adjunctive immunotherapeutic approach in the context of HIV infection.

\section{Methods}

Animals and virus infection. Eighteen female RMs (Macaca mulatta) of Chinese origin, aged 4-5 years, were confirmed prior to infection as seronegative for simian $\mathrm{T}$ leukemia virus type 1 , simian retrovirus type 1 (type D retrovirus), herpes B viruses, and SIVmac. All animals were housed in compliance with French regulations for animal care and use and were inoculated intravenously with the pathogenic SIVmac251 strain (ten 50\% animal infectious doses). The pathogenic SIVmac251 isolate was provided by A.M. Aubertin (INSERM U74, Strasbourg, France) and was titrated in Chinese RMs by intravenous inoculation. RMs of Chinese origin are useful for monitoring immune dynamics, as their pathology closely mimics that in humans (17). Animals $(n=6)$ were treated with Q-VD-OPH (SM Biochemicals; the compound was diluted in sterile physiological water in the presence of 15\% DMSO) at a dose of $20 \mathrm{mg} / \mathrm{kg}$ by the intravenous route (1 bolus was injected via the saphenous vein) on days 5, 7, 9,11, and 14 after infection. Untreated, control animals were included, one group receiving the placebo (sterile water/DMSO) $(n=6)$ and a second group receiving sterile water only $(n=6)$. Because no difference was observed between the 2 control groups, animals were pooled. In our cohort of Chinese RMs, we assessed TRIM5a polymorphism. Seventeen of them displayed TRIM5a $^{\text {TFP/TFP }}$, while only 1 RM was TRIM5a ${ }^{\text {TFP/Q }}$. Thus, Q/Q was extremely rare, consistent with previous report (114). Q-VD-OPH is a pan-caspase inhibitor $(115,116)$, previously reported to block caspase activity in neuronal and ischemia pathologies $(55,117)$. All surgery was performed under sodium pentobarbital anesthesia, and all efforts were made to minimize suffering. The animals were euthanized for ethical reasons when they showed weight loss greater than $10 \%$, repetitive diarrhea, and declining $\mathrm{CD} 4^{+} \mathrm{T}$ cell counts.

Pharmacokinetics of Q-VD-OPH in RMs. A pharmacokinetic analysis in naive animals using 2 doses of Q-VD-OPH (20 and $40 \mathrm{mg} / \mathrm{kg}$ ) was performed. Q-VD-OPH was quantified in the serum samples at $\mathrm{O}$, $0.25,0.5,1,2,4,8$, and 24 hours and in LNs at 4 hours after intravenous injection. Protein precipitation with acetonitrile was used for sera. LNs were homogenized using a Precellys tissue homogenizer (Bertin Technologies) with a 1:2 v/v water/acetonitrile mixture. Q-VD-OPH was quantified using a Waters ACQUITY ultra-performance liquid chromatography (UPLC) system with a $2.1 \times 50-\mathrm{mm}, 1.7-\mathrm{m}$ ACQUITY UPLC BEH RP18 shield column coupled to a Waters Qua9ro Premier TQ mass spectrometer operated in positive ion electrospray and multiple reaction monitoring (MRM) mode.

Determination of viral load and quantitative assessment of DNAinfected cells. RNA was extracted from the serum of SIV-infected RMs by using a Tri Reagent BD kit (Molecular Research Center Inc.). Real-time quantitative reverse transcriptase-PCR was used to determine serum viral loads. The frequency of SIV-infected cells was determined as previ- 
ously reported (13) by limiting-dilution PCR of sorted CD4+ $\mathrm{T}$ cells from peripheral blood mononuclear cells (PBMCs), LNs, and spleen of SIVinfected RMs. Cells were lysed with TPK buffer (10 mM Tris- $\mathrm{HCl}$ [pH 8.3], $50 \mathrm{mM} \mathrm{KCl}, 2.5 \mathrm{mM} \mathrm{MgCl}_{2}, 0.5 \%$ Nonidet P-40, 0.5\% Tween 20, $100 \mu \mathrm{g} / \mathrm{ml}$ proteinase $\mathrm{K}$ ). After incubation for 1 hour at $56^{\circ} \mathrm{C}$, proteinase $\mathrm{K}$ was inactivated at $95^{\circ} \mathrm{C}$ for 10 minutes. We subjected 20 limitingdilution replicates to a nested PCR. SIV proviral DNA was amplified by nested PCR with SIVmac251-specific primers surrounding the nef region. After 35 cycles $\left(95^{\circ} \mathrm{C}\right.$ for 30 seconds, $60^{\circ} \mathrm{C}$ for 30 seconds, and $72^{\circ} \mathrm{C}$ for 1 minute) with the first set of primers, Preco (5'-CAGAGGCTCTCTGCGACCCTAC) and K3 (5'-GACTGAATACAGAGCGAAATGC), we amplified a fragment of $961 \mathrm{bp}$. We then reamplified $10 \mu \mathrm{l}$ of product $\left(30\right.$ cycles of $95^{\circ} \mathrm{C}$ for 30 seconds, $55^{\circ} \mathrm{C}$ for 30 seconds, and $72^{\circ} \mathrm{C}$ for 1 minute) with primers $\mathrm{K} 1$ (5'-TGGAAGATGGATCCTCGCAATCC) and A2 (5'-GGACTAATTTCCATAGCCAGCCA). The limiting-dilution PCR method detected 1 SIV $\mathrm{DNA}^{+}$cell in 10,000 uninfected cells (CEMX174) validated with SIV-1C cells (provided by F. Villinger, University of Louisiana at Lafayette, Lafayette, Louisiana, USA), which contain a single provirus of SIVmac251 per cell.

Cell proliferation and cell death quantification. PBMCs were isolated from blood by density gradient centrifugation. Fresh cells were incubated for 24 hours at $37^{\circ} \mathrm{C}$ with $5 \% \mathrm{CO}_{2}$ in RPMI 1640 supplemented with $10 \%$ FCS (AbCys), penicillin $(50 \mathrm{U} / \mathrm{ml})$, streptomycin $(50 \mathrm{U} / \mathrm{ml})$, glutamine $(2 \mathrm{mM})$, and sodium pyruvate $(1 \mathrm{mM})$. PBMCs $\left(5 \times 10^{5}\right.$ cells/well $)$ were incubated in the presence of an reverse transcriptase inhibitor (dideoxyinosine [ddI]: $1 \mu \mathrm{M})$ for 6 days with HIV-2 antigen (10 $\mu \mathrm{g} / \mathrm{ml}$, Bio-Rad), as previously described (13). The addition of ddI was required to prevent viral replication, which induces cell death in proliferating T cells $(35,36)$. $\left[{ }^{3} \mathrm{H}\right]$ thymidine $(1 \mu \mathrm{Ci})$ was added for the last overnight culture to monitor cell proliferation. Experiments were performed in triplicate.

Cells were cultured in 24-well culture plates (BD Biosciences) at a concentration of $5 \times 10^{5} /$ well in the absence or presence of rhCD95L (200 ng/ml). Cell death was assessed after overnight culture by flow cytometry. Briefly, after staining with specific Abs (30 minutes at $4^{\circ} \mathrm{C}$ ), cells were washed and then incubated with fluorescently labeled annexin V (20 minutes at $\left.4^{\circ} \mathrm{C}\right)$. Cells were gated on FSC and SSC parameters, and 20,000 events $\left(\mathrm{CD}^{+} \mathrm{CD}^{+}\right.$or $\mathrm{CD}^{+} \mathrm{CD} 8^{+} \mathrm{T}$ cells) were analyzed on flow cytometer. Percentages of CD45RA ${ }^{+} \mathrm{CD} 62 \mathrm{~L}^{+}$(naive), CD45RA ${ }^{-} \mathrm{CD}_{62 \mathrm{~L}^{+}}$(central memory, Tcm), CD45RA-CD62L- (effector memory, Tem), and CD45RA ${ }^{+} \mathrm{CD}_{62 \mathrm{~L}^{-}}$(terminal differentiated) $\mathrm{T}$ cell subsets undergoing death were quantified $(14,15)$. Samples were acquired on a Cytomics FC 500 flow cytometer (Beckman Coulter Life Sciences) and analyzed using FlowJo software (version 10.06).

Lymphocyte immunophenotyping by flow cytometry. T cell immunophenotyping was performed on fresh cells by staining with the following fluorochrome-labeled monoclonal antibodies: anti-CD3 (clone SP34 and SP34-2; BD Biosciences), anti-human CD4 (clone M-T477; BD Biosciences), anti-human CD8 (clone RPA-T8; BD Biosciences), anti-human CD45RA (clone 2H4; Beckman Coulter), and CD62L (clone SK11; BD Biosciences). Antibodies were added to $100 \mu \mathrm{l}$ whole blood collected in EDTA or to $2 \times 10^{5} \mathrm{LN}$ cells. Cells were incubated for 15 minutes at room temperature. Erythrocytes were lysed with $2 \mathrm{ml}$ of diluted IOTest 3 lysing solution (Beckman Coulter). The cells then were washed once in PBA buffer (PBS, $1 \%$ BSA, $10 \mathrm{mM} \mathrm{NaN}_{3}$ ) and resuspended in PBS containing 1\% paraformaldehyde (PBS-PF) (15).

For $\mathrm{T}$ cell intracellular staining (75), cells were incubated in the presence of brefeldin A ( $5 \mu \mathrm{g} / \mathrm{ml}$ for the last 12 hours) before being stained with anti-CD4 and anti-CD3 mAbs (BD Biosciences), then washed twice in PBS, and further incubated with TNF- $\alpha$ and anti-IFN- $\gamma$ (clone 4S.B3; BD Biosciences) after membrane permeabilization. Cells were examined for expression of perforin, granzyme B, granulysin, and TIA1 after cell surface staining and then fixed/permeabilized with a Cytofix/Cytoperm Kit (BD Biosciences), according to manufacturer's instructions, and stained intracellularly for perforin (clone Pf344, Mabtech), granzyme B (clone GRB04, Invitrogen), granulysin (ebioDH2, eBioscience), and TIA1 (clone PNIM3293, Beckman Coulter) (75). Samples were acquired on a Cytomics FC 500 flow cytometer and analyzed using FlowJo software (version 10.06).

Quantitation of FasL, IL-18, and SCD14 in sera of SIV-infected monkeys. FasL in serum was measured using ELISA (MBL). The assay uses anti-FasL mAbs (clones 4H9 and 4A5). The peroxidase substrate was used to quantify FasL and the optical density measured at 450 $\mathrm{nm}$. Concentration was determined using a standard curve based on recombinant FasL (61). IL-18 was measured by using an ELISA kit (MBL Biomedical, CliniSciences). The concentration was determined using a standard curve based on recombinant IL-18 (58). Commercial ELISA was used to measure SCD14 (R\&D Systems).

Reagents. Reagents used in the study included AEBSF, aprotinin, elastinal, and TLCK (Tosyl-L-lysyl-chloromethane hydrochloride), which inhibit serine proteases, purchased from Sigma-Aldrich; E64 and leupeptin, which inhibit cysteine proteases, purchased from SigmaAldrich; pepstatin A, which inhibits aspartyl proteases, purchased from Sigma-Aldrich; 1,10-phenanthroline, an inhibitor of metallopeptidases, purchased from Sigma-Aldrich; $N$-acetyl-Leu-Leu-norleucinal (ALLN), calpeptin, calpastatin, and Z-FA-CHO, which inhibit calpain proteases, purchased from Calbiochem; Z-Phe-Gly-NHO-Bz, an inhibitor of cysteine cathepsins, purchased from Calbiochem; and Q-VD-OPH, a broad caspase inhibitor, purchased from Calbiochem.

Statistics. Data are reported as mean $\pm \mathrm{SEM}$, and groups were compared using Mann-Whitney $U$ test or paired Student's $t$ test with Prism version 6.0 (GraphPad Software). AUC was also calculated; a $P$ value less than 0.05 was considered significant.

Study approval. All animal experiments described in the present study were conducted at the Institute Pasteur according to the European Union guidelines for the handling of laboratory animals (http:// ec.europa.eu/environment/chemicals/lab_animals/home_en.htm). The numbers of animals treated with the compound were defined according to the European guidelines for nonhuman primates and the 3Rs principles (Replacement, Reduction and Refinement). The protocol was approved by the Committee on the Ethics of Animal Experiments of Île de France (PARIS 1, \#20080007).

\section{Author contributions}

$\mathrm{ML}, \mathrm{AS}$, and JE conceived and designed the experiments. ML, RS, VR, JG, LCG, SM, VM, MCC, AP, and HR performed the experiments. ML, RS, VR, JG, LCG, SM, VM, MCC, AP, HR, AC, BH, GS, AS, and JE analyzed the data. ML, RS, VR, GS, and JE wrote the manuscript.

\section{Acknowledgments}

This article is dedicated to the memory of Bruno Hurtrel. We also thank Jean-Claude Ameisen for his initial support. We acknowledge Céline Gommet (Institut Pasteur) for her expertise in the follow-up of our primate cohort. We also acknowledge François Villinger, who performed TRIM5a polymorphism. ML and JG 
were supported by fellowships from ANRS. RS thanks Fundação para a Ciência e a Tecnologia (FCT) for Investigator FCT Grant IF/00021/2014. This study was supported by research funding from ANRS and CIHR (MOP-133476) to JE. VR is supported by a fellowship from FCT (code SFRH/BD/64064/2009). JE thanks the Canada Research Chair program for financial assistance.
Address correspondence to: Jérôme Estaquier, Centre de Recherche du CHU de Québec, 2705, Boul. Laurier, Quebec City, Quebec G1V 4G2, Canada. Phone: 418.656.4141; Email: estaquier@yahoo.fr. Or to: Mireille Laforge, CNRS FR 3636, Université Paris Descartes, 45 rue des Saint-Pères, Paris, France. Phone: 01.42.86.41.38; Email: mireille.laforge@parisdescartes.fr.
1. Ho DD, Neumann AU, Perelson AS, Chen W, Leonard JM, Markowitz M. Rapid turnover of plasma virions and CD4 lymphocytes in HIV-1 infection. Nature. 1995;373(6510):123-126.

2. Mohri $\mathrm{H}$, et al. Increased turnover of T lymphocytes in HIV-1 infection and its reduction by antiretroviral therapy. JExp Med. 2001;194(9):1277-1287.

3. Weant AE, Michalek RD, Khan IU, Holbrook BC, Willingham MC, Grayson JM. Apoptosis regulators Bim and Fas function concurrently to control autoimmunity and $\mathrm{CD}^{+} \mathrm{T}$ cell contraction. Immunity. 2008;28(2):218-230.

4. Hutcheson J, et al. Combined deficiency of proapoptotic regulators Bim and Fas results in the early onset of systemic autoimmunity. Immunity. 2008;28(2):206-217.

5. Hughes PD, Belz GT, Fortner KA, Budd RC, Strasser A, Bouillet P. Apoptosis regulators Fas and Bim cooperate in shutdown of chronic immune responses and prevention of autoimmunity. Immunity. 2008;28(2):197-205.

6. Hurtrel B, Petit F, Arnoult D, Müller-Trutwin M, Silvestri G, Estaquier J. Apoptosis in SIV infection. Cell Death Differ. 2005;12(suppl 1):979-990.

7. Estaquier J, et al. Programmed cell death and AIDS: significance of T-cell apoptosis in pathogenic and nonpathogenic primate lentiviral infections. Proc Natl Acad Sci U S A. 1994;91(20):9431-9435.

8. Ameisen JC, Estaquier J, Idziorek T. From AIDS to parasite infection: pathogen-mediated subversion of programmed cell death as a mechanism for immune dysregulation. Immunol Rev. 1994;142:9-51.

9. Estaquier E, et al. T helper type 1/T helper type 2 cytokines $T$ cell death: preventive effect of interleukin 12 on activation-induced CD95 (FAS/ APO-1)-mediated apoptosis of $\mathrm{CD} 4^{+} \mathrm{T}$ cells from human immunodeficiency virus-infected persons. J Exp Med. 1995;182(6):1759-1767.

10. Katsikis PD, Wunderlich ES, Smith CA, Herzenberg LA, Herzenberg LA. Fas antigen stimulation induces marked apoptosis of T lymphocytes in human immunodeficiency virus-infected individuals. J Exp Med. 1995;181(6):2029-2036.

11. Finkel TH, et al. Apoptosis occurs predominantly in bystander cells and not in productively infected cells of HIV- and SIV-infected lymph nodes. Nat Med. 1995;1(2):129-134.

12. Silvestri G, et al. Divergent host responses during primary simian immunodeficiency virus SIVsm infection of natural sooty mangabey and nonnatural rhesus macaque hosts. J Virol. 2005;79(7):4043-4054.

13. Monceaux V, et al. Extensive apoptosis in lymphoid organs during primary SIV infection predicts rapid progression towards AIDS. AIDS. 2003;17(11):1585-1596.

14. Arnoult D, et al. Caspase-dependent and -independent T-cell death pathways in pathogenic simian immunodeficiency virus infection: relationship to disease progression. Cell Death Differ. 2003;10(11):1240-1252.

15. Viollet L, et al. Death of CD $4^{+} \mathrm{T}$ cells from lymph nodes during primary SIVmac251 infection predicts the rate of AIDS progression. JImmunol. 2006;177(10):6685-6694.

16. Cumont MC, et al. Early divergence in lymphoid tissue apoptosis between pathogenic and nonpathogenic simian immunodeficiency virus infections of nonhuman primates. J Virol. 2008;82(3):1175-1184.

17. Monceaux V, et al. CD $4^{+} \mathrm{CCR} 5^{+} \mathrm{T}$-cell dynamics during simian immunodeficiency virus infection of Chinese rhesus macaques. J Virol. 2007;81(24):13865-13875.

18. Muro-Cacho CA, Pantaleo G, Fauci AS. Analysis of apoptosis in lymph nodes of HIV-infected persons. Intensity of apoptosis correlates with the general state of activation of the lymphoid tissue and not with stage of disease or viral burden. J Immunol. 1995;154(10):5555-5566.

19. Silvestri G, et al. Nonpathogenic SIV infection of sooty mangabeys is characterized by limited bystander immunopathology despite chronic high-level viremia. Immunity. 2003;18(3):441-452.

20. Gougeon ML, et al. Programmed cell death in peripheral lymphocytes from HIV-infected persons: increased susceptibility to apoptosis of CD4 and CD8 T cells correlates with lymphocyte activation with disease progression. J Immunol. 1996;156(9):3509-3520.

21. Estaquier J, Tanaka M, Suda T, Nagata S, Golstein P, Ameisen JC. Fas-mediated apoptosis of $\mathrm{CD}^{+}$ and $\mathrm{CD}^{+} \mathrm{T}$ cells from human immunodeficiency virus-infected persons: differential in vitro preventive effect of cytokines protease antagonists. Blood. 1996;87(12):4959-4966.

22. Desbarats J, Freed JH, Campbell PA, Newell MK. Fas (CD95) expression death-mediating function are induced by CD 4 cross-linking on $\mathrm{CD}^{+}{ }^{+} \mathrm{T}$ cells. Proc Natl Acad Sci U S A. 1996;93(20):11014-11018.

23. Petit F, et al. Role of CD95-activated caspase-1 processing of IL- $1 \beta$ in TCR-mediated proliferation of HIV-infected CD4(+) T cells. Eur J Immunol. 2001;31(12):3513-3524.

24. Lelièvre JD, et al. A novel mechanism for HIV1-mediated bystander CD4 ${ }^{+}$T-cell death: neighboring dying cells drive the capacity of HIV1 to kill noncycling primary CD4 ${ }^{+} \mathrm{T}$ cells. Cell Death Differ. 2004;11(9):1017-1027.

25. Sloand EM, Young NS, Kumar P, Weichold FF, Sato T, Maciejewski JP. Role of Fas ligand and receptor in the mechanism of T-cell depletion in acquired immunodeficiency syndrome: effect on $\mathrm{CD}^{+}$ lymphocyte depletion human immunodeficiency virus replication. Blood. 1997;89(4):1357-1363.
26. Sloand EM, et al. The role of interleukin-converting enzyme in Fas-mediated apoptosis in HIV-1 infection. JClin Invest. 1998;101(1):195-201.

27. lida K, Kurita K, Tange K, Yoshida K. Necrosis of the articular tubercle after repeated injections of sodium hyaluronate in the temporomandibular joint. A case report. Int J Oral Maxillofac Surg. 1998;27(4):278-279.

28. Alam A, Cohen LY, Aouad S, Sékaly RP. Early activation of caspases during $\mathrm{T}$ lymphocyte stimulation results in selective substrate cleavage in nonapoptotic cells. J Exp Med. 1999;190(12):1879-1890.

29. Mouhamad S, Arnoult D, Auffredou MT, Estaquier J, Vazquez A. Differential modulation of interleukin-2-and interleukin-4-mediated early activation of normal human $\mathrm{B}$ lymphocytes by the caspase inhibitor zVAD-fmk. Eur Cytokine Netw. 2002;13(4):439-445.

30. Fraietta JA, et al. Type I interferon upregulates Bak and contributes to T cell loss during human immunodeficiency virus (HIV) infection. PLoS Pathog. 2013;9(10):e1003658.

31. Naora H, Gougeon ML. Interleukin- 15 is a potent survival factor in the prevention of spontaneous but not CD95-induced apoptosis in CD4 CD8 T lymphocytes of HIV-infected individuals. Correlation with its ability to increase BCL-2 expression. Cell Death Differ. 1999;6(10):1002-1011.

32. Mueller YM, Makar V, Bojczuk PM, Witek J, Katsikis PD. IL-15 enhances the function inhibits CD95/Fas-induced apoptosis of human CD4 ${ }^{+}$ $\mathrm{CD}^{+}$effector-memory T cells. Int Immunol. 2003;15(1):49-58.

33. Terai C, Kornbluth RS, Pauza CD, Richman DD, Carson DA. Apoptosis as a mechanism of cell death in cultured T lymphoblasts acutely infected with HIV-1. JClin Invest. 1991;87(5):1710-1715.

34. Laurent-Crawford AG, et al. The cytopathic effect of HIV is associated with apoptosis. Virology. 1991;185(2):829-839.

35. Petit F, et al. Productive HIV-1 infection of primary CD4+ T cells induces mitochondrial membrane permeabilization leading to a caspase-independent cell death. J Biol Chem. 2002;277(2):1477-1487.

36. Laforge M, Petit F, Estaquier J, Senik A. Commitment to apoptosis in CD4(+) T lymphocytes productively infected with human immunodeficiency virus type 1 is initiated by lysosomal membrane permeabilization, itself induced by the isolated expression of the viral protein Nef. J Virol. 2007;81(20):11426-11440.

37. Moutouh L, Estaquier J, Richman DD, Corbeil J. Molecular and cellular analysis of human immunodeficiency virus-induced apoptosis in lymphoblastoid T-cell-line-expressing wild-type and mutated CD4 receptors. J Virol. 1998;72(10):8061-8072. 
38. Gandhi RT, Chen BK, Straus SE, Dale JK, Lenardo MJ, Baltimore D. HIV-1 directly kills $\mathrm{CD} 4^{+} \mathrm{T}$ cells by a Fas-independent mechanism. J Exp Med. 1998;187(7):1113-1122.

39. Mattapallil JJ, Douek DC, Hill B, Nishimura Y, Martin M, Roederer M. Massive infection and loss of memory $\mathrm{CD} 4^{+} \mathrm{T}$ cells in multiple tissues during acute SIV infection. Nature. 2005;434(7037):1093-1097.

40. Laforge $\mathrm{M}$, et al. DRAM triggers lysosomal membrane permeabilization and cell death in CD4(+) T cells infected with HIV. PLoS Pathog. 2013;9(5):e1003328.

41. Banda NK, et al. Crosslinking CD 4 by human immunodeficiency virus gp120 primes $\mathrm{T}$ cells for activation-induced apoptosis. JExp Med. 1992;176(4):1099-1106.

42. Estaquier J, et al. Effects of antiretroviral drugs on human immunodeficiency virus type 1-induced CD4(+) T-cell death. J Virol. 2002;76(12):5966-5973.

43. Lelièvre JD, Petit F, Arnoult D, Ameisen JC, Estaquier J. Interleukin 7 increases human immunodeficiency virus type $1 \mathrm{LAI}$-mediated Fas-induced T-cell death. J Virol. 2005;79(5):3195-3199.

44. Herbein G, et al. Apoptosis of CD8 ${ }^{+} \mathrm{T}$ cells is mediated by macrophages through interaction of HIV gp120 with chemokine receptor CXCR4. Nature. 1998;395(6698):189-194.

45. Berndt C, Möpps B, Angermüller S, Gierschik P, Krammer PH. CXCR4 and CD4 mediate a rapid CD95-independent cell death in CD4(+) T cells. Proc Natl Acad Sci U S A. 1998;95(21):12556-12561.

46. Esser MT, et al. Differential incorporation of CD45, CD80 (B7-1), CD86 (B7-2), major histocompatibility complex class I II molecules into human immunodeficiency virus type 1 virions microvesicles: implications for viral pathogenesis immune regulation.J Virol. 2001;75(13):6173-6182.

47. Vlahakis SR, et al. Chemokine-receptor activation by env determines the mechanism of death in HIV-infected and uninfected T lymphocytes. J Clin Invest. 2001;107(2):207-215.

48. Holm GH, et al. Apoptosis of bystander T cells induced by human immunodeficiency virus type 1 with increased envelope/receptor affinity coreceptor binding site exposure. J Virol. 2004;78(9):4541-4551.

49. Doitsh $\mathrm{G}$, et al. Abortive HIV infection mediates CD4 $\mathrm{T}$ cell depletion and inflammation in human lymphoid tissue. Cell. 2010;143(5):789-801.

50. Li Q, et al. Peak SIV replication in resting memory $\mathrm{CD} 4+\mathrm{T}$ cells depletes gut lamina propria $\mathrm{CD} 4{ }^{+} \mathrm{T}$ cells. Nature. 2005;434(7037):1148-1152.

51. Cicala C, et al. HIV-1 envelope induces activation of caspase- 3 and cleavage of focal adhesion kinase in primary human CD4(+) T cells. Proc Natl Acad Sci U S A. 2000;97(3):1178-1183.

52. Doitsh $\mathrm{G}$, et al. Cell death by pyroptosis drives CD4 T-cell depletion in HIV-1 infection. Nature. 2014;505(7484):509-514.

53. Espert L, et al. Autophagy is involved in T cell death after binding of HIV-1 envelope proteins to CXCR4. J Clin Invest. 2006;116(8):2161-2172.

54. Janin A, et al. CD95 engagement induces disseminated endothelial cell apoptosis in vivo: immunopathologic implications. Blood. 2002;99(8):2940-2947.
55. Melnikov VY, Faubel S, Siegmund B, Lucia MS, Ljubanovic D, Edelstein CL. Neutrophilindependent mechanisms of caspase-1- and IL-18-mediated ischemic acute tubular necrosis in mice. J Clin Invest. 2002;110 (8):1083-1091.

56 . Gu Y, et al. Activation of interferon-gamma inducing factor mediated by interleukin- $1 \beta$ converting enzyme. Science. 1997;275(5297):206-209.

57. Ghayur T, et al. Caspase- 1 processes IFN- $\gamma$ inducing factor and regulates LPS-induced IFN- $\gamma$ production. Nature. 1997;386(6625):619-623.

58. Campillo-Gimenez L, et al. AIDS progression is associated with the emergence of IL-17-producing cells early after simian immunodeficiency virus infection. JImmunol. 2010;184(2):984-992.

59. Campillo-Gimenez L, et al. Nonpathogenesis of simian immunodeficiency virus infection is associated with reduced inflammation and recruitment of plasmacytoid dendritic cells to lymph nodes, not to lack of an interferon type I response, during the acute phase. J Virol. 2010;84(4):1838-1846.

60. Badley AD, et al. In vivo analysis of Fas/FasL interactions in HIV-infected patients. J Clin Invest. 1998;102(1):79-87.

61. Laforge M, et al. HIV/SIV infection primes monocytes and dendritic cells for apoptosis. PLoS Pathog. 2011;7(6):e1002087.

62. Tsutsui H, et al. IL-18 accounts for both TNF- $\alpha$ and Fas ligand-mediated hepatotoxic pathways in endotoxin-induced liver injury in mice. JImmunol. 1997;159(8):3961-3967.

63. Hashimoto W, et al. Differential antitumor effects of administration of recombinant IL-18 or recombinant IL-12 are mediated primarily by FasFas ligand-perforin-induced tumor apoptosis, respectively. JImmunol. 1999;163(2):583-589.

64 . Wang $X$, et al. Monitoring $\alpha 4 \beta 7$ integrin expression on circulating $\mathrm{CD}^{+}{ }^{+} \mathrm{T}$ cells as a surrogate marker for tracking intestinal $\mathrm{CD} 4^{+} \mathrm{T}$-cell loss in SIV infection. Mucosal Immunol. 2009;2(6):518-526.

65. Brenchley JM, et al. Microbial translocation is a cause of systemic immune activation in chronic HIV infection. Nat Med. 2006;12(12):1365-1371.

66. Estes JD, et al. Damaged intestinal epithelial integrity linked to microbial translocation in pathogenic simian immunodeficiency virus infections. PLoS Pathog. 2010;6(8):e1001052.

67. Klatt NR, et al. Loss of mucosal CD103+ DCs and $\mathrm{IL}^{-17^{+}}$and IL-22 $2^{+}$lymphocytes is associated with mucosal damage in SIV infection. Mucosal Immunol. 2012;5(6):646-657.

68. Sandler NG, et al. Plasma levels of soluble CD14 independently predict mortality in HIV infection. J Infect Dis. 2011;203(6):780-790.

69. Chevalier MF, et al. The Th17/Treg ratio, IL-1RA and SCD14 levels in primary HIV infection predict the T-cell activation set point in the absence of systemic microbial translocation. PLoS Pathog. 2013;9(6):e1003453.

70. Serrano-Villar S, et al. HIV-infected individuals with low $\mathrm{CD} 4 / \mathrm{CD} 8$ ratio despite effective antiretroviral therapy exhibit altered $\mathrm{T}$ cell subsets, heightened $\mathrm{CD} 8^{+} \mathrm{T}$ cell activation, increased risk of non-AIDS morbidity mortality. PLoS Pathog. 2014;10(5):e1004078.

71. Hansen SG, et al. Profound early control of highly pathogenic SIV by an effector memory T-cell vac- cine. Nature. 2011;473(7348):523-527.

72. Hansen SG, et al. Effector memory T cell responses are associated with protection of rhesus monkeys from mucosal simian immunodeficiency virus challenge. Nat Med. 2009;15(3):293-299.

73. Chomont N, et al. HIV reservoir size and persistence are driven by $\mathrm{T}$ cell survival and homeostatic proliferation. Nat Med.2009;15(8):893-900.

74. Paiardini M, et al. Low levels of SIV infection in sooty mangabey central memory $\mathrm{CD}(4)(+) \mathrm{T}$ cells are associated with limited CCR 5 expression. Nature medicine. 2011;17(7):830-836.

75. Monceaux V, et al. $\mathrm{CD} 8^{+} \mathrm{T}$ cell dynamics during primary simian immunodeficiency virus infection in macaques: relationship of effector cell differentiation with the extent of viral replication. JImmunol. 2005;174(11):6898-6908.

76. Fukazawa $\mathrm{Y}$, et al. Lymph node $\mathrm{T}$ cell responses predict the efficacy of live attenuated SIV vaccines. Nat Med. 2012;18(11):1673-1681.

77. Lubong Sabado R, et al. In vitro priming recapitulates in vivo HIV-1 specific T cell responses, revealing rapid loss of virus reactive $\mathrm{CD} 4$ $\mathrm{T}$ cells in acute HIV-1 infection. PLoS One. 2009;4(1):e4256.

78. García F, et al. A dendritic cell-based vaccine elicits $\mathrm{T}$ cell responses associated with control of HIV-1 replication. Sci Transl Med. 2013;5(166):166ra2.

79. Casazza JP, et al. Acquisition of direct antiviral effector functions by $\mathrm{CMV}$-specific $\mathrm{CD} 4^{+} \mathrm{T}$ lymphocytes with cellular maturation. J Exp Med. 2006;203(13):2865-2877.

80. Brown DM, Dilzer AM, Meents DL, Swain SL. CD4 T cell-mediated protection from lethal influenza: perforin and antibody-mediated mechanisms give a one-two punch. J Immunol. 2006;177(5):2888-2898.

81. Pike R, et al. Race between retroviral spread and $\mathrm{CD} 4^{+} \mathrm{T}$-cell response determines the outcome of acute Friend virus infection. J Virol. 2009;83(21):11211-11222.

82. Khanna R, et al. Class I processing-defective Burkitt's lymphoma cells are recognized efficiently by $\mathrm{CD}^{+} \mathrm{EBV}$-specific CTLs. J Immunol. 1997;158(8):3619-3625

83. Fang M, et al. Perforin-dependent $\mathrm{CD}^{+}{ }^{+} \mathrm{T}$-cell cytotoxicity contributes to control a murine poxvirus infection. Proc Natl Acad Sci U S A. 2012;109(25):9983-9988.

84. Zhou W, et al. Functional characterization of $\mathrm{BK}$ virus-specific $\mathrm{CD} 4^{+} \mathrm{T}$ cells with cytotoxic potential in seropositive adults. Viral Immunol. 2007;20(3):379-388.

85. Appay V, et al. Characterization of CD4(+) CTLs ex vivo. J Immunol. 2002;168(11):5954-5958.

86. Zaunders JJ, et al. Identification of circulating antigen-specific $\mathrm{CD} 4^{+} \mathrm{T}$ lymphocytes with a $\mathrm{CCR}^{+}$, cytotoxic phenotype in an HIV-1 longterm nonprogressor in CMV infection. Blood. 2004;103(6):2238-2247.

87. Norris PJ, et al. Beyond help: direct effector functions of human immunodeficiency virus type 1-specific CD4(+) T cells. JVirol. 2004;78(16):8844-8851.

88. Sacha JB, et al. Gag- and Nef-specific CD4 $4^{+} \mathrm{T}$ cells recognize and inhibit SIV replication in infected macrophages early after infection. Proc Natl Acad 
Sci U S A. 2009;106(24):9791-9796.

89. Soghoian DZ, et al. HIV-specific cytolytic $\mathrm{CD} 4 \mathrm{~T}$ cell responses during acute HIV infection predict disease outcome. Sci Transl Med. 2012;4(123):123ra25.

90. Yerly S, et al. Time of initiation of antiretroviral therapy: impact on HIV-1 viraemia. The Swiss HIV Cohort Study. AIDS. 2000;14(3):243-249.

91. Ngo-Giang-Huong N, et al. Proviral HIV-1 DNA in subjects followed since primary HIV-1 infection who suppress plasma viral load after one year of highly active antiretroviral therapy. AIDS. 2001;15(6):665-673.

92. Oxenius A, et al. Early highly active antiretroviral therapy for acute HIV-1 infection preserves immune function of $\mathrm{CD} 8^{+}$and $\mathrm{CD}^{+} \mathrm{T}$ lymphocytes. Proc Natl Acad Sci U S A. 2000;97(7):3382-3387.

93. Rosenberg ES, et al. Immune control of HIV-1 after early treatment of acute infection. Nature. 2000;407(6803):523-526.

94. Byrareddy SN, et al. Sustained virologic control in $\mathrm{SIV}+$ macaques after antiretroviral and $\alpha 4 \beta 7$ antibody therapy. Science. 2016;354(6309):197-202.

95. Ortiz AM, et al. Depletion of CD $4^{+} \mathrm{T}$ cells abrogates post-peak decline of viremia in SIV-infected rhesus macaques. JClin Invest. 2011;121(11):4433-4445.

96. Elbim C, et al. Early divergence in neutrophil apoptosis between pathogenic and nonpathogenic simian immunodeficiency virus infections of nonhuman primates. JImmunol. 2008;181(12):8613-8623.

97. Moir S, et al. Decreased survival of B cells of HIV-viremic patients mediated by altered expression of receptors of the TNF superfamily. JExp Med. 2004;200(7):587-599.

98. Ullrich CK, Groopman JE, Ganju RK. HIV-1 gp120- and gp160-induced apoptosis in cultured endothelial cells is mediated by caspases. Blood . 2000;96(4):1438-1442.

99. Shi B, et al. Apoptosis induced by HIV-1 infection of the central nervous system. JClin Invest. 1996;98(9):1979-1990.

100.Whitney JB, et al. Rapid seeding of the viral reservoir prior to SIV viraemia in rhesus monkeys. Nature. 2014;512(7512):74-77.

101. Borducchi EN, et al. Ad26/MVA therapeutic vaccination with TLR7 stimulation in SIV-infected rhesus monkeys. Nature. 2016;540(7632):284-287.

102. Monceaux V, Ho Tsong Fang R, Cumont MC, Hurtrel B, Estaquier J. Distinct cycling CD4(+)and CD8(+)-T-cell profiles during the asymptomatic phase of simian immunodeficiency virus SIVmac251 infection in rhesus macaques. J Virol. 2003;77(18):10047-10059.

103. Watson A, et al. Plasma viremia in macaques infected with simian immunodeficiency virus: plasma viral load early in infection predicts survival. J Virol. 1997;71(1):284-290.

104.Staprans SI, et al. Simian immunodeficiency virus disease course is predicted by the extent of virus replication during primary infection. J Virol. 1999;73(6):4829-4839.

105. Arnoult D, Petit F, Lelièvre JD, Estaquier J. Mitochondria in HIV-1-induced apoptosis. Biochem Biophys Res Commun. 2003;304(3):561-574.

106. Gauduin MC, et al. Induction of a virus-specific effector-memory $\mathrm{CD} 4^{+} \mathrm{T}$ cell response by attenuated SIV infection. JExp Med. 2006;203(12):2661-2672.

107. Johnson S, et al. Cooperativity of HIV-specific cytolytic CD4 T cells and CD8 T cells in control of HIV viremia. J Virol. 2015;89(15):7494-7505.

108. Brenner B, Wainberg MA. We need to use the best antiretroviral drugs worldwide to prevent HIV drug resistance. AIDS. 2016;30(17):2725-2727.

109. Hogquist KA, Unanue ER, Chaplin DD. Release of IL-1 from mononuclear phagocytes. J Immunol. 1991;147(7):2181-2186.

110. Ray K, et al. Investigation of guanine-nucleotidebinding protein involvement and regulation of cyclic AMP metabolism in interleukin 1 signal transduction. Biochem J. 1992;282(pt 1):59-67.

111. Thornberry NA, et al. A novel heterodimeric cysteine protease is required for interleukin-1 $\beta$ processing in monocytes. Nature. 1992;356(6372):768-774.

112. Li DQ, Tseng SC. Three patterns of cytokine expression potentially involved in epithelialfibroblast interactions of human ocular surface. JCell Physiol. 1995;163(1):61-79.

113. Poonia B, Salvato MS, Yagita H, Maeda T, Okumura K, Pauza CD. Treatment with anti-FasL antibody preserves memory lymphocytes and virus-specific cellular immunity in macaques challenged with simian immunodeficiency virus. Blood.2009;114(6):1196-1204.

114. de Groot NG, Heijmans CM, Koopman G, Verschoor EJ, Bogers WM, Bontrop RE. TRIM5 allelic polymorphism in macaque species/ populations of different geographic origins: its impact on SIV vaccine studies. Tissue Antigens. 2011;78(4):256-262.

115. Caserta TM, Smith AN, Gultice AD, Reedy MA, Brown TL. Q-VD-OPh, a broad spectrum caspase inhibitor with potent antiapoptotic properties. Apoptosis. 2003;8(4):345-352.

116. Chauvier D, Ankri S, Charriaut-Marlangue C, Casimir R, Jacotot E. Broad-spectrum caspase inhibitors: from myth to reality? Cell Death Differ. 2007;14(2):387-391.

117. Braun JS, Prass K, Dirnagl U, Meisel A, Meisel C. Protection from brain damage and bacterial infection in murine stroke by the novel caspase-inhibitor Q-VD-OPH. Exp Neurol. 2007;206(2):183-191. 